\title{
INVENTARIO FLORÍSTICO DE LA COMUNIDAD LACANDONA De Nahá, Chiapas, MÉXico
}

\author{
Alejandro Durán-Fernández', Juan Rogelio Aguirre-Rivera², \\ José García-Pérez ${ }^{2}$, Samuel Levy-Tacher ${ }^{4}$ y José Arturo de Nova-VÁzquez ${ }^{2,3,5}$ \\ 'Comisión Nacional de Áreas Naturales Protegidas, Tamuín, San Luis Potosí, México \\ 2Instituto de Investigación de Zonas Desérticas, Universidad Autónoma de San Luis Potosí, \\ San Luis Potosí, San Luis Potosí, México \\ ${ }^{3}$ Facultad de Agronomía y Veterinaria, Universidad Autónoma de San Luis Potosí, \\ Soledad de Graciano Sánchez, San Luis Potosí, México \\ ${ }^{4}$ El Colegio de la Frontera Sur, Unidad San Cristóbal de las Casas, San Cristóbal de las Casas, Chiapas, México \\ ${ }^{5}$ Autor para la correspondencia: arturo.denova@uaslp.mx
}

\begin{abstract}
Resumen: La comunidad lacandona de Nahá se localiza al norte de la selva lacandona, en el municipio de Ocosingo, estado de Chiapas; su vegetación aún conserva áreas de selva madura y el resto es objeto de aprovechamiento tradicional diversificado e intensificado. Los resultados indican que la flora vascular preliminar está compuesta por 118 familias, 344 géneros y 504 especies, principalmente de la selva alta perennifolia. Diez especies fueron registradas en alguna categoría de riesgo con base en la Norma Oficial Mexicana (NOM-059-SEMARNAT-2010). Dentro de la región resaltan los árboles como las formas biológicas más abundantes, seguidos de las hierbas, epífitas y arbustos. Se registró el nombre común para 366 especies y algún uso para 239 de ellas. Se presentan 25 nuevos registros para 22 especies no registradas previamente en Chiapas y tres para México. La riqueza de especies y el estado de conservación de la vegetación madura del área estudiada le confiere importancia para su conservación. El conocimiento tradicional de los lacandones ha permitido mantener dicha diversidad a pesar de la constante presión de desarrollo que representan los poblados circundantes. De esta manera el presente estudio justifica de manera adicional el decreto de esta región como Área Natural Protegida.
\end{abstract}

Palabras clave: Florística, nombres y usos tradicionales, riqueza específica, selva alta perennifolia.

\begin{abstract}
The Lacandon community Nahá is located at the north of the Lacandon rain forest, at the Municipality of Ocosingo, Chiapas; their vegetation preserves some areas with mature rain forest and the rest is subject to traditional diversified and intensified use. Results indicate that the preliminary vascular flora includes 118 families, 344 genera and 504 species, mainly in the rain forest. Ten species are listed in some risk category in the Norma Oficial Mexicana (NOM-059-SEMARNAT-2010). Trees are the more abundant life forms in the region, followed by herbaceous, epiphytes, and shrubs. Common names for 366 species were recorded, and some use for 239 of them. Twenty-five new records are presented for 22 species not previously reported for Chiapas, and three for México. The species richness and conservation status of the mature vegetation in the studied area highlight the importance for its conservation. Traditional knowledge of Lacandon people has maintained this diversity in spite of the constant developmental pressures by the human establishments surrounding the area.
\end{abstract}

Key words: Floristics, species richness, tropical rain forest, traditional names and uses.

M éxico representa uno de los principales puntos críticos de biodiversidad en el mundo, debido a sus características orográficas y posición geográfica, que lo sitúan en un lugar privilegiado con múltiples y ricas comunidades vegetales (Rzedowski 1978, 1998; Toledo y Ordóñez, 1998; Challenger y Soberón, 2008). Un ejemplo importante de esta biodiversidad son las selvas perennifolias, ubicadas en regiones donde la precipitación promedio anual es mayor que $2,000 \mathrm{~mm}$, con una distribución y temperatura relativamente homogénea. El área original de estas selvas abarcaba aproximadamente $9.1 \%$ del territorio nacional (INEGI, 2003), pero de acuerdo con estimaciones más recientes se 
ha reducido a sólo $4.82 \%$, y se considera que incluyen más que 5,000 especies de plantas vasculares (Challenger y Soberón, 2008), esto es, cerca del $17 \%$ de la flora de México, estimada en unas 30,000 especies (Villaseñor, 2004).

La región lacandona es una amplia extensión de clima cálido húmedo de aproximadamente 1,300,000 ha, localizada al este y noroeste del estado de Chiapas, la cual contiene los remanentes más extensos de selvas altas perennifolias de México y es refugio de un número importante de especies de flora y fauna (Levy-Tacher et al., 2006; Avila-Torresagatón et al., 2012). Con sólo $0.16 \%$ de la superficie del país, se considera que esta región cuenta con más que $20 \%$ del total de las especies existentes en México. Su biota ayuda a mantener la estabilidad del clima, la pureza del aire, la disponibilidad del agua y la fertilidad del suelo; además, muchas de estas especies son importantes como medicamento, alimento, ornato o madera (Ricker y Daly, 1998; Levy-Tacher et al., 2002, 2004). Así la selva de la región lacandona ha sido considerada por diversas entidades nacionales e internacionales como una de las áreas de mayor prioridad para su conservación en el país. En menos de cinco décadas la cobertura selvática de esta región ha disminuido en más del $50 \%$, como consecuencia de un fuerte proceso de colonización, expansión de las vías de comunicación, la tala inmoderada y la incorporación de nuevas áreas al aprovechamiento agrícola y pecuario (Miranda, 1952; MuenchNavarro, 1978; Rzedowski, 1978; Nations y Nigh, 1980; Casco-Montoya, 1984; Vásquez-Sánchez y Ramos-Olmos, 1992; Challenger y Soberón, 2008).

Según Miranda (1953), las exploraciones botánicas en Chiapas se iniciaron con José Mariano Mociño en 1796; posteriormente, distinguidos naturalistas como Carl Albert Purpus, Eizi Matuda y Faustino A. Miranda González entre otros, han contribuido notablemente al conocimiento ecológico, florístico y de vegetación en el estado. Excelentes crónicas, síntesis histórica y alcances de las exploraciones botánicas se detallan en Miranda (1953) y Breedlove (1981). En relación con trabajos sobre la vegetación regional cabe señalar los de Miranda (1952, 1961), Calzada y Valdivia (1979), Breedlove (1981), Meave-del Castillo (1990), Castillo-Campos y Narave (1992) y García-Gil y Lugo-Hupb (1992), quienes incluyen listas de especies presentes en sus áreas de estudio respectivas.

Los estudios antes señalados y los trabajos florísticos de Breedlove (1986) para el estado y de Martínez et al. (1994) en nivel regional, conforman la flora de Chiapas, posiblemente una de las mejor documentadas del país, pero aún incompleta. En efecto, la realización de inventarios locales, con el respaldo de los grupos étnicos correspondientes permiten, por ejemplo, complementar la información florística y enriquecer el conocimiento sobre diversas especies, particularmente sobre aspectos ecológicos y de utilización (Levy-Tacher et al., 2002, 2004, 2012; Levy-Tacher y Aguirre-Rivera, 2005).
La comunidad lacandona de Nahá conserva rodales maduros de selva alta perennifolia, como parte fundamental de su sistema de aprovechamiento tradicional persistente y diversificado de la cobertura vegetal de sus tierras y actualmente es una de las Áreas Naturales Protegidas de México, registrada como Área de Protección de Flora y Fauna Nahá desde el 28 de noviembre de 2003 (CONANP, 2006). La etnia lacandona constituye el único grupo realmente autóctono de la región y posee un conocimiento tradicional sobre las formas de aprovechamiento de la flora y vegetación regional, mediante el sistema de roza, tumba y quema para el manejo del suelo (Levy-Tacher y Aguirre-Rivera, 2005). Así, el objetivo de este trabajo fue contribuir al conocimiento de la flora regional, mediante la elaboración de una lista anotada de las plantas vasculares en la localidad de Nahá, ubicada al norte de la selva lacandona.

\section{Materiales y métodos}

Zona de estudio. El estudio se realizó en los bienes comunales de la comunidad lacandona de Nahá (Figura 1), decretada como Área de Protección de Flora y Fauna en 2003, con una superficie aproximada de $3,847.41$ ha, la cual se localiza entre los paralelos $16^{\circ} 56^{\prime}$ y $17^{\circ} 02^{\prime}$ de latitud norte y los meridianos $91^{\circ} 33^{\prime}$ y $91^{\circ} 39^{\prime}$ de longitud oeste (INEGI, 1988a). Müllerried (1957) incluyó esta porción de la región lacandona dentro de lo que denominó región natural de montañas marginales del norte y oriente de Chiapas. Su fisiografía está formada por serranías bajas, con elevaciones que alcanzan 800 a 1,200 m s.n.m., alternadas con valles, geoformas que Muench-Navarro (1978) consideró como serranías y terrazas antiguas. Geológicamente predominan las calizas del Cretácico superior (Müllerried, 1957; INEGI, 1988b). El sistema fluvial superficial se manifiesta en una exigua red de ríos y arroyos que desembocan en los ríos Tulijá y Santo Domingo-Chocoljá, los cuales drenan en dirección sureste-noroeste y forman parte de la gran cuenca del Usumacinta (Müllerried, 1957; INEGI,1988a). Asimismo, en la zona de estudio se encuentra la laguna de Nahá de origen cárstico, importante para el asentamiento poblacional de los lacandones, la cual forma parte del sistema endorreico que desagua también en la misma cuenca por medio de galerías subterráneas. El clima, según el sistema de Köppen modificado por García (1973), es cálido húmedo con lluvias abundantes en el verano y parte del otoño, y una temporada seca corta de marzo a abril (Aw2(w)(i')g). La temperatura media anual es de $25{ }^{\circ} \mathrm{C}$ y la precipitación total anual alcanza hasta los 2,500 mm (Muench-Navarro, 1978; INEGI, 1988c). Los suelos predominantes son rendzinas y litosoles, de coloración roja y gris, respectivamente; son suelos poco desarrollados que no sobrepasan $50 \mathrm{~cm}$ de espesor, generalmente arcillosos (Muench-Navarro, 1978). Miranda (1952), quien dividió en regiones florísticas el estado de Chiapas, denominó "llanuras y declives del norte del macizo central" 


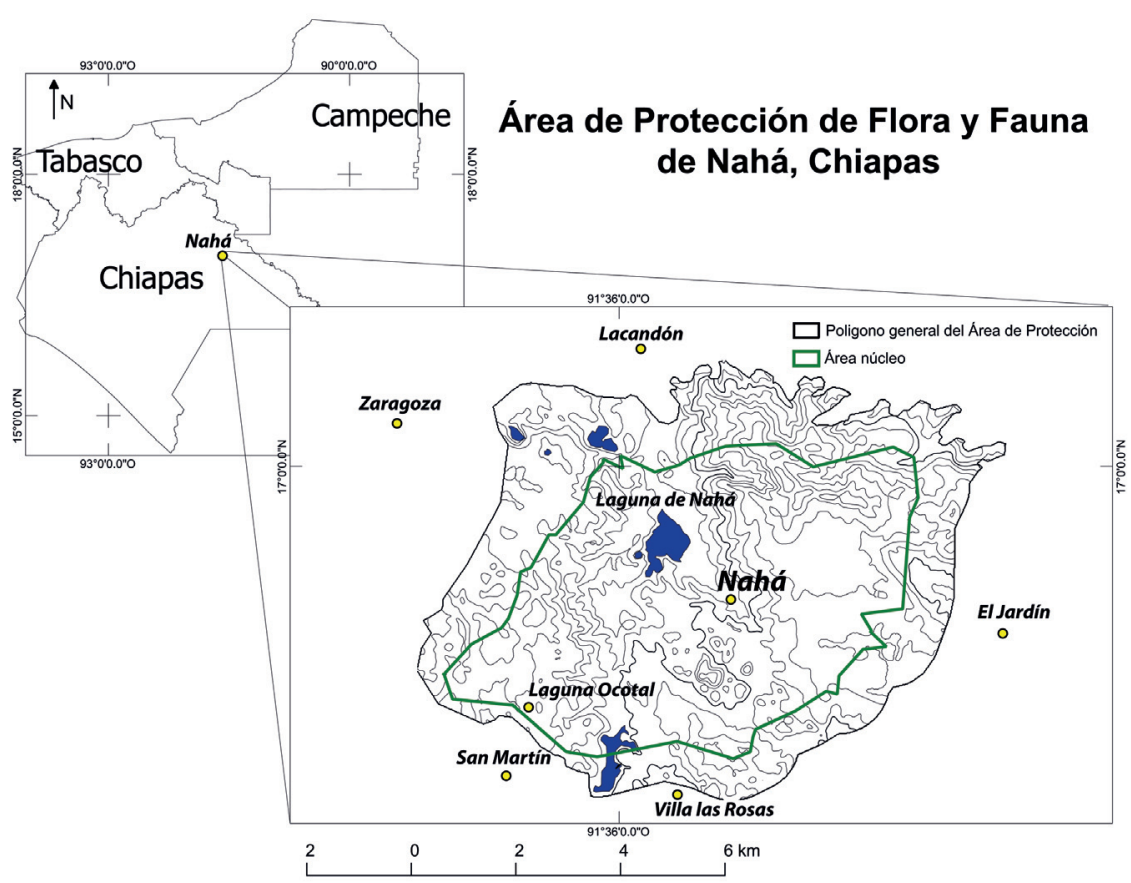

Figura 1. Localización de la comunidad de Nahá en la selva Lacandona, Chiapas, México.

a la región donde se localiza la comunidad de estudio. Las condiciones climáticas y edáficas descritas favorecen el desarrollo de la selva alta y mediana perennifolia (Miranda, 1952, 1961; Miranda y Hernández X., 1963; Rzedowski, 1978; INEGI, 1988d).

Recolectas. La comunidad de Nahá fue seleccionada en función de: 1) La existencia de áreas con vegetación madura. 2) Aprovechamiento tradicional de la vegetación, diversificado e intensificado. 3) La aceptación de las autoridades (comunales y municipales), y de la población para realizar la investigación. Después de que el proyecto fue aceptado por la comunidad, se planteó la necesidad de contar con guías para realizar el trabajo de campo. Así, se conformó un equipo de trabajo con personas nativas (de origen lacandón) como informantes seleccionados en calidad de ayudantes (destacados conocedores de la flora y vegetación regional), a quienes se les habilitó para auxiliar en la realización de los muestreos de vegetación y las recolectas botánicas, y para que fungieran como intérpretes en las entrevistas, en caso de ser necesario.

Las recolectas botánicas se realizaron entre noviembre de 1993 y julio de 1999 en dos etapas. Los bienes de la comunidad de Nahá comprenden una superficie de unas 5,000 ha. Dentro de estas tierras, con ayuda de la información cartográfica de INEGI y recorridos de campo con los informantes, se procedió a reconocer áreas diferentes con características físicas homogéneas.

Para la primer etapa que comprendió de noviembre de 1993 a mayo de 1995, en cada uno de los sitios ubicados, se localizaron los rodales de selva alta perennifolia más madura y se registró el historial de uso de estas áreas, con el fin de seleccionar las menos perturbadas. Se inven- tariaron 25 muestras de $400 \mathrm{~m}^{2}(20 \times 20)$ cada una, una hectárea en total. Los cuadros de muestreo se ubicaron sistemáticamente, para cubrir unas 3,500 ha. La distancia entre los cuadros de muestreo varió entre 0.5 y $3.0 \mathrm{~km}$. En la segunda etapa, que comprendió de febrero de 1997 a julio de 1999, las recolectas botánicas se ampliaron a las especies presentes en otros sitios y a especies de interés etnobotánico ausentes en los sitios de muestreo de la primer etapa, como las zonas de vegetación hidrófila lacustre, acahuales, milpas y solares.

Para cada espécimen recolectado se asignó la forma biológica de acuerdo con Font Quer (1953) y el tipo de vegetación o sitio donde se encuentra. Además, se aplicó el método de entrevista dirigida a informantes seleccionados por muestreo de juicio para registrar así la información sobre los usos y nombres comunes de las especies (AguirreRivera, 1979).

Los especímenes recolectados se depositaron en el herbario Isidro Palacios (SLPM) de la Universidad Autónoma de San Luis Potosí, con duplicados en el herbario MEXU, del Instituto de Biología de la Universidad Nacional Autónoma de México. La identificación se llevó a cabo principalmente en el herbario Isidro Palacios, con base en literatura especializada, y en algunos casos con ayuda de especialistas en algunas familias. La nomenclatura se revisó consultando la base en línea The Plant List (<http://www.theplantlist.org/> consultada en enero 2016), pero considerando en cada caso la información más aceptada por los principales especialistas de grupos. La clasificación de los helechos se basó en el sistema de Christenhusz et al. (2011) y para las angiospermas se usó el sistema APG III (APG, 2009). 


\section{Resultados}

Grupos taxonómicos y especies en riesgo. Los especímenes de herbario generados corresponden a 20 meses de recolecta repartidos entre los años 1993 a 1999. La curva de acumulación de especies recolectadas en función del esfuerzo de muestreo (Figura 2) indica que este inventario es confiable pues se alcanza una asíntota en el número de especies, considerando además que los últimos meses corresponden a la segunda etapa en que se exploraron regiones perturbadas. En los bienes comunales de la comunidad lacandona de Nahá se registraron 504 especies de plantas vasculares que corresponden a 344 géneros, representantes de 118 familias (Apéndice 1). Los taxones registrados pertenecen a tres grupos taxonómicos principales. Angiospermae es el mejor representado con 482 especies, $95.63 \%$ del total registrado, de las cuales 355 son Eudicotiledóneas, 99 Monocotiledóneas, 27 Magnólidas y un Nymphaeales. Mientras que el grupo taxonómico de helechos y afines (Lycophyta y Monilophyta) incluyó el $3.97 \%$ de las especies totales con 20 especies, y Gimnospermae tan sólo el $0.4 \%$ con dos especies (Tabla 1). Las familias mejor representadas fueron Ru-

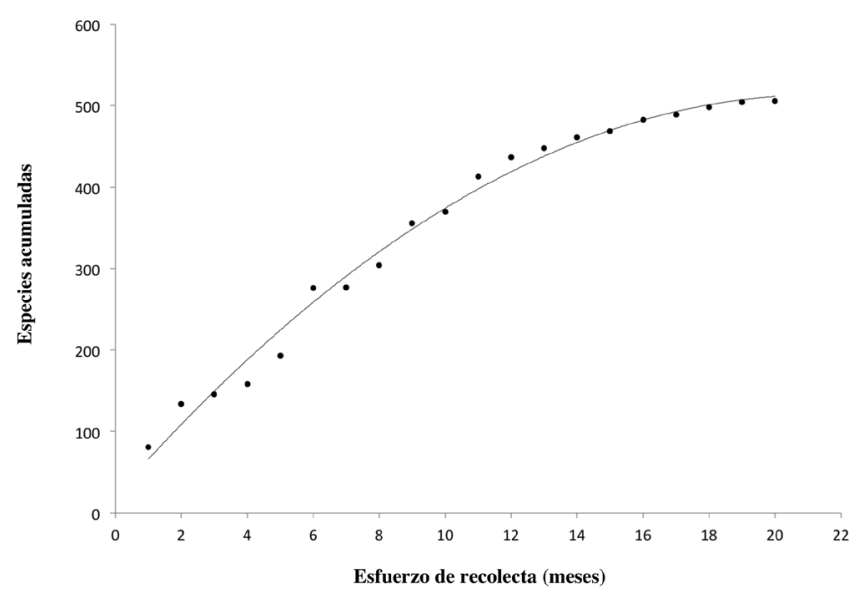

Figura 2. Acumulación de especies registradas para la comunidad de Nahá durante los 20 meses de muestreo.

Tabla 1. Número de táxones de la flora vascular registrados en los bienes de la comunidad lacandona de Nahá, Chiapas, México.

\begin{tabular}{lccc}
\hline Grupo taxonómico & Familias & Géneros & Especies \\
\hline Lycophyta & 2 & 2 & 2 \\
Monilophyta & 9 & 17 & 18 \\
Gimnospermae & 2 & 2 & 2 \\
Angiospermae & & & \\
$\quad$ Nymphaeales & 1 & 1 & 1 \\
$\quad$ Mangnólidas & 7 & 16 & 27 \\
$\quad$ Monocotiledóneas & 20 & 64 & 99 \\
$\quad$ Eudicotiledóneas & 77 & 242 & 355 \\
\hline Total & 118 & 343 & 504 \\
\hline
\end{tabular}

Tabla 2. Familias con mayor número de especies en la flora vascular de los bienes de la comunidad lacandona de Nahá, Chiapas, México.

\begin{tabular}{lcccc}
\hline Familias & $\begin{array}{c}\text { Géneros } \\
\text { Número }\end{array}$ & Número & $\begin{array}{c}\text { Especies } \\
\text { Porcentaje } \\
\text { del total }\end{array}$ & $\begin{array}{c}\text { Porcentaje } \\
\text { acumulado }\end{array}$ \\
\hline Rubiaceae & 18 & 39 & 7.74 & 7.74 \\
Fabaceae & 22 & 38 & 7.54 & 15.28 \\
Orchidaceae & 23 & 38 & 7.54 & 22.82 \\
Asteraceae & 23 & 27 & 5.36 & 28.17 \\
Melastomataceae & 5 & 17 & 3.37 & 31.55 \\
Poaceae & 13 & 17 & 3.37 & 34.92 \\
Bromeliaceae & 4 & 11 & 2.18 & 37.10 \\
Euphorbiaceae & 7 & 11 & 2.18 & 39.29 \\
Lauraceae & 4 & 10 & 1.98 & 41.27 \\
Malvaceae & 9 & 10 & 1.98 & 43.25 \\
Apocynaceae & 9 & 9 & 1.79 & 45.04 \\
Sapindaceae & 6 & 9 & 1.79 & 46.83 \\
Araceae & 5 & 8 & 1.59 & 48.41 \\
Myrtaceae & 5 & 8 & 1.59 & 50.00 \\
Primulaceae & 3 & 8 & 1.59 & 51.59 \\
\hline
\end{tabular}

biaceae (7.74 \%), Fabaceae (7.54 \%), Orchidaceae (7.54\%), Asteraceae $(5.36 \%)$, Melastomataceae $(3.37 \%)$ y Poaceae (3.37\%; Tabla 2).

Con base en la NOM-059-SEMARNAT-2010 se registraron diez especies con alguna categoría de riesgo: Calophyllum brasiliense Cambess., Chamaedorea pinnatifrons (Jacq.) Oerst. y Talauma mexicana (DC.) G.Don están consideradas en peligro de extinción; Chamaedorea metallica O.F.Cook ex H.E.Moore está en la categoría de amenazada; mientras que Croton guatemalensis Lotsy, Hamelia rovirosae Wernham, Podocarpus matudae Lundell, Prosthe-

Tabla 3. Formas biológicas y tipos de nutrición atípicos de las plantas vasculares registradas en los bienes de la comunidad lacandona de Nahá, Chiapas, México.

\begin{tabular}{lccc}
\hline Forma biológica & Acrónimo & \multicolumn{2}{c}{ Especies } \\
& & Número & $\begin{array}{c}\text { Porcentaje } \\
\text { del total }\end{array}$ \\
\hline Árbol & $\mathrm{Ar}$ & 200 & 39.60 \\
Herbácea & $\mathrm{He}$ & 107 & 21.19 \\
Epífita & $\mathrm{Ep}$ & 62 & 12.28 \\
Trepadora & $\mathrm{Te}$ & 39 & 7.72 \\
Liana & $\mathrm{Li}$ & 37 & 7.33 \\
Arbusto & $\mathrm{Ab}$ & 34 & 6.73 \\
Hemiepífita arbórea & $\mathrm{Har}$ & 10 & 1.98 \\
Hemiepífita arbustiva & $\mathrm{Hab}$ & 3 & 0.59 \\
Palma & $\mathrm{Pa}$ & 7 & 1.39 \\
Parásita & $\mathrm{Par}$ & 4 & 0.79 \\
Saprófita & $\mathrm{Sa}$ & 2 & 0.40 \\
Total & & 505 & 100.00 \\
\hline
\end{tabular}


InVENTARIO Florístico de NAHÁ, Chiapas

Tabla 4. Usos de las plantas vasculares registradas en los bienes de la comunidad lacandona de Nahá, Chiapas, México.

\begin{tabular}{|c|c|c|c|c|c|}
\hline Usos & Núm. de especies & $\begin{array}{l}\text { Familias con } \\
\text { mayores usos }\end{array}$ & $\begin{array}{c}\text { Núm. de especies } \\
\text { usadas (Núm. de usos) }\end{array}$ & Forma biológica & $\begin{array}{c}\text { Núm. de especies } \\
\text { usadas (Núm. de usos) }\end{array}$ \\
\hline ALIM & 70 & Fabaceae & $20(26)$ & $\mathrm{Ar}$ & 143 (239) \\
\hline MACO & 52 & Rubiaceae & $20(26)$ & $\mathrm{He}$ & $28(29)$ \\
\hline MEDI & 50 & Malvaceae & $9(16)$ & $\mathrm{Te}$ & $18(23)$ \\
\hline LEÑA & 40 & Orchidaceae & $9(9)$ & $\mathrm{Li}$ & $18(18)$ \\
\hline ALFA & 26 & Euphorbiaceae & $8(10)$ & $\mathrm{Ab}$ & $13(15)$ \\
\hline ARTE & 18 & Arecaceae & $7(12)$ & $\mathrm{Pa}$ & $7(12)$ \\
\hline INTR & 15 & Lauraceae & $7(10)$ & Ep & $9(9)$ \\
\hline FIBR & 12 & Melastomataceae & $7(8)$ & Har & $4(6)$ \\
\hline CEMI & 8 & Myrtaceae & $7(10)$ & & \\
\hline ORNA & 8 & Araceae & $6(9)$ & & \\
\hline UTDO & 8 & Bignoniaceae & $6(7)$ & & \\
\hline CERE & 7 & Primulaceae & $6(9)$ & & \\
\hline COLO & 6 & Sapindaceae & $6(8)$ & & \\
\hline AROM & 4 & Cucurbitaceae & $5(5)$ & & \\
\hline ENVO & 4 & Meliaceae & $5(13)$ & & \\
\hline FUAG & 4 & Sapotaceae & $5(16)$ & & \\
\hline $\mathrm{JABO}$ & 3 & & & & \\
\hline JUGUE & 3 & & & & \\
\hline VENT & 3 & & & & \\
\hline $\mathrm{CHIC}$ & 2 & & & & \\
\hline EMBA & 2 & & & & \\
\hline MEAN & 2 & & & & \\
\hline RESI & 2 & & & & \\
\hline CEVI & 1 & & & & \\
\hline INSE & 1 & & & & \\
\hline VEST & 1 & & & & \\
\hline
\end{tabular}

Finalidades de uso reconocidas: alimento para fauna (ALFA); alimento (ALIM); aromática (AROM); artesanal (ARTE); cera y miel (CEMI); ceremonial (CERE); cerco vivo (CEVI); chicle (CHIC); colorante (COLO); embarbascar peces (EMBA); envoltura para alimentos (ENVO); fibra (FIBR); fuente de agua (FUAG); insecticida (INSE); instrumentos de trabajo (INTR); jabón (JABO); juguete (JUGE); leña (LEÑA); materiales para construcción (MACO); medicamento para animales (MEAN); medicinal (MEDI); ornamental (ORNA); resina (RESI); utensilios de uso doméstico (UTDO); venta (VENT); vestido (VEST). Formas biológicas: árbol (Ar); arbusto (Ab); epífita (Ep); hemiepífita arbórea (Har); herbácea perenne (He); liana (Li); palma (Pa); trepadora (Te).

chea neurosa (Ames) W.E.Higgins, Tillandsia festucoides Brongn. ex Mez y Vanilla planifolia Andrews están sujetas a protección especial.

Formas biológicas. En la Tabla 3 se presentan las proporciones de las 11 formas biológicas reconocidas en el área de estudio. Los árboles son los más abundantes, con $39.6 \%$ de las especies registradas, de 60 familias botánicas como Rubiaceae (13.43\%), Fabaceae (9.45 \%), Malvaceae $(4.98 \%)$, Lauraceae $(4.48 \%)$, Melastomataceae $(4.48 \%)$, Euphorbiaceae $(3.48 \%)$ y Rosaceae $(3.48 \%)$. El $21.19 \%$ de las especies son hierbas perennes de 47 familias botánicas, de las cuales Poaceae (15.98 \%), Fabaceae $(11.21 \%)$ y Asteraceae $(10.28 \%)$ las que resaltan con mayor número de especies. El $12.27 \%$ de las especies registradas son epífitas, de 11 familias botánicas, resaltando Orchidaceae $(56.45 \%)$ y Bromeliaceae $(17.74 \%)$, este porcentaje se incrementa hasta el $14.85 \%$ sí se incluyen a las hemiepífitas (ocho familias botánicas adicionales). Un $6.73 \%$ de las especies son arbustos de 15 familias, como Rubiaceae $(20.59 \%)$, Asteraceae $(14.71 \%)$ y Verbenaceae $(11.76 \%)$. La menos representada son las palmas (1.38 \%) sólo en Arecaceae. De los tipos de nutrición peculiares se tienen parásitas $(0.79 \%)$ de Lorantaceae y Santalaceae y saprófitas $(0.39 \%)$ de Gentianaceae y Triuridaceae.

Tipos de vegetación. Del total recolectado para toda el área de estudio, 418 especies (82.77\%) fueron propias de la selva alta perennifolia (Apéndice 1). De estas, 279 especies $(55.2 \%)$ fueron registradas en los inventarios de selva alta perennifolia más madura. Para los otros tipos de vegetación, 66 especies $(13.06 \%)$ se encontraron en acahuales o vegetación secundaria, 16 (3.16\%) correspondieron a plantas cultivadas en milpa o solares y nueve $(1.78 \%)$ se recolectaron en vegetación hidrófila lacustre (Apéndice 1). 
Usos y nombres comunes. El conocimiento botánico tradicional de los lacandones de Nahá se concretó en la distinción de 366 especies con algún nombre común, pertenecientes a 96 familias botánicas y se registró al menos un uso para 239 de ellas (Apéndice 1, Tabla 4). El uso con mayor número de registros fue como alimento (70 especies; $19.89 \%$ ), seguido de materiales para la construcción (52 especies; $14.77 \%$ ), medicinal (50 especies; $14.20 \%$ ), leña (40 especies; $11.36 \%$ ), alimento para fauna (26 especies; $7.39 \%$ ), artesanal (18 especies; $5.11 \%$ ), instrumentos de trabajo (15 especies; $4.26 \%$ ) y fibras (12 especies; $3.41 \%$ ). Otros usos menos frecuentes, registrados fueron: ornamental, utensilios de uso doméstico, cera, miel, colorantes, aromáticas, envolturas, fuente de agua, venta, jabón, juguete, chicle, embarbascar, medicamento para animales, cerco vivo, insecticida y resina. Las familias con un mayor número de especies usadas fueron Fabaceae (20 especies; $8.37 \%$ ), Rubiaceae (20 especies; $8.37 \%$ ), Malvaceae (nueve especies; $3.77 \%$ ), Orquidaceae (nueve especies; $3.77 \%$ ), Euphorbiaceae (ocho especies; $3.35 \%$ ), Arecaceae (siete especies; $2.93 \%$ ), Lauraceae (siete especies; 2.9 3\%), Melastomataceae (siete especies; $2.93 \%$ ), Myrtaceae (siete especies; $2.93 \%$ ), Araceae (siete especies; $2.93 \%$ ), Bignoniaceae (seis especies; $2.51 \%$ ), Primulaceae (seis especies; $2.51 \%$ ), Sapindaceae (seis especies; $2.51 \%$ ). A la vez, resaltan las familias Arecaceae, Malvaceae, Meliaceae y Sapotaceae como polivalentes, con múltiples usos para sus especies (Tabla 4). Respecto a la relación uso y forma de vida de las especies, resaltan en primer término los árboles, con un total de 239 diferentes usos dados a 142 especies, superando por mucho al siguiente grupo en importancia, las hierbas con 28 especies y 29 usos distintos, las trepadoras con 18 especies y 23 usos, las lianas con 18 especies y 18 usos, los arbustos con 13 especies y 15 usos, las palmas con siete especies y 12 usos, las epífitas con nueve especies y nueve usos y las hemiepífitas arbóreas con cuatro especies y nueve usos.

\section{Discusión}

La riqueza específica registrada en el área muestreada de selva alta perennifolia más madura (1 ha) es similar a la encontrada por Meave-del Castillo (1990), que incluye 267 especies de plantas vasculares en el muestreo de una hectárea de selva alta perennifolia en Bonampak, Chiapas; aunque estos datos florísticos son congruentes con los resultados aquí presentados, es necesario señalar que dicho autor excluyó del recuento a las plantas epífitas, a las trepadoras, a los árboles con diámetro menor que $3.3 \mathrm{~cm}$ a la altura del pecho. Por su parte, Bongers et al. (1988) encontraron resultados similares con base en el muestreo de una hectárea de selva alta en Los Tuxtlas, Veracruz, donde reconocieron 234 especies de árboles, arbustos, lianas y hierbas, además de registrar 58 especies de epífitas y hemiepífitas. Nuestra lista para toda el área de estudio comprende 504 especies, las cua- les, como dato indicativo, representan $11.7 \%$ del número de especies estimado para toda la región de Chiapas conocida como Selva Lacandona (4,315 especies; según Martínez et al., 1994), y concuerda con el estudio similar realizado en las tierras de la comunidad lacandona de Lacanhá Chansayab, Chiapas, donde se registraron 485 especies de plantas vasculares (Levy-Tacher et al., 2006).

Los resultados muestran que en tan sólo diez familias $(11.8 \%)$, con 10 a 39 especies cada una, se agrupan poco más que $43 \%$ de todas las especies registradas en la zona, mientras que las 108 familias restantes contribuyen con un poco menos que $57 \%$. Por otra parte, 53 familias (44.9\%) están representadas sólo por una especie. El porcentaje alto de familias representadas por una única especie ha sido considerado como un indicador o tendencia propia de ecosistemas maduros y complejos (Margalef, 1974; Odum, 1985). En otras investigaciones realizadas en selvas perennifolias, se ha encontrado una tendencia similar (SarukhánKermez, 1968; Hubbell y Foster, 1983; Vázquez-Torres, 1989; Gentry, 1990; Levy-Tacher et al., 2006). Las familias de mayor relevancia (Rubiaceae, Fabaceae, Orchidaceae y Asteraceae) y los géneros con mayor riqueza de especies (Psychotria L., Epidendrum L., Tillandsia L., Miconia Ruiz \& Pav., Ardisia Sw., Chamaedorea Willd., Cissus L., Clusia L. y Saurauia Willd.) en general corresponden a las familias y géneros mejor representados en las selvas estudiadas en México por Meave-del Castillo (1990), Bongers et al. (1988) y Levy-Tacher et al. (2006), así como también en las selvas neotropicales mencionadas por Gentry (1990).

La proporción de formas biológicas presentes en el área de estudio concuerda con los espectros documentados en otras zonas de selvas perennifolias (Bongers et al., 1988; VázquezTorres, 1989; Levy-Tacher et al., 2006), donde los árboles y en menor proporción las hierbas, epífitas, trepadoras, lianas y arbustos, son los grupos mejor representados. El conjunto de formas vitales que exhibe la selva alta perennifolia es extremadamente rico y complejo, como consecuencia de la evolución adaptativa de los caracteres morfológicos de las plantas a las condiciones ambientales que ocupan en los diferentes niveles de la estructura vertical de dicha formación vegetal (Rzedowski, 1978; Ehrendorfer, 1986).

Los registros nuevos y las especies ausentes en las listas florísticas de la región selva lacandona, y que en este trabajo son documentadas seguramente por vez primera, son probablemente poco significativos en comparación con la presumible riqueza regional, pero el hecho es que aún faltaban por recolectarse y registrarse para dicha región. Los registros nuevos aquí anotados son evidencia de la importancia de los inventarios florístico en la zona, y particularmente con la recolecta sistemática y permanente de especies vegetales para mejorar el conocimiento botánico de la región. Así, por ejemplo, Trichilia quadrijuga subsp. cinerascens (C.DC.) T.D.Penn. (Meliaceae) es probablemente un 
nuevo registro para México; la literatura y los ejemplares de herbario revisados, indican que solamente es conocida de Nicaragua a Panamá, de manera que con el hallazgo de Nahá se amplía significativamente su área de distribución. Otras recolectas que probablemente sean nuevos registros para México son Billia rosea (Planch. \& Linden) C.Ulloa \& M.Jørg. (Sapindaceae) y Miconia barbinervis (Benth.) Triana (Melastomataceae), de distribución conocida sólo en Centro y Sudamérica.

Entre las especies recolectadas en Nahá y ausentes en los trabajos florísticos más amplios, como los de Breedlove (1986) y Martínez et al. (1994) para Chiapas y la región Lacandona, respectivamente, ni tampoco anotadas en la Flora Mesoamericana volumen 6 (Davidse et al., 1994) y volumen 1 (Davidse et al., 1995), son: Acanthaceae: Justicia fimbriata (Nees) V.A.W.Graham; Apocynaceae: Tassadia obovata Decne.; Aquifoliaceae: Ilex costaricensis Donn. Sm.; Araceae: Philodendron standleyi Grayum; Arecaceae: Chamaedorea metallica O.F.Cook ex H.E.Moore; Asteraceae: Bidens bipontina Sherff, Calea integrifolia (DC.) Hemsl. y Sinclairia deppeana Rydb.; Bromeliaceae: Tillandsia pseudobaileyi C.S.Gardner; Capparaceae: Capparidastrum mollicellum (Standl.) Cornejo \& Iltis; Convolvulaceae: Ipomoea batatoides Choisy; Cucurbitaceae: Cucurbita argyrosperma K.Koch; Euphorbiaceae: Euphorbia hyssopifolia L.; Fabaceae: Calliandra tergemina var. emarginata (Humb. \& Bonpl. ex Willd.) Barneby, Leucaena pulverulenta (Schltdl.) Benth. y Psoralea rhombifolia Torr. \& A.Gray; Myrtaceae: Calyptranthes schiedeana O.Berg.; Orchidaceae: Habenaria pringlei B.L.Rob. y Erycina pusilla (L.) N.H.Williams \& M.W.Chase; Rubiaceae: Hoffmannia nicotianifolia (M.Martens \& Galeotti) L.O.Williams y Psychotria panamensis Standl.; y Styracaceae: Styrax warscewiczii Perkins.

Las novedades aportadas por Nahá para la flora de la región selva lacandona y México, a partir de un área estudiada relativamente pequeña, se pueden explicar en buena parte por el enfoque aplicado al proceso de recolecta: vinculación con inventarios estructurales exhaustivos en vegetación madura, complementación con otros rodales similares y los derivados de ellos, y el respaldo de los botánicos tradicionales lacandones.

Respecto a la relación entre utilidad y forma biológica o vital, el número notablemente mayor de especies útiles fue de árboles. Este resultado fue similar al obtenido por Levy-Tacher et al. (2002) para la comunidad lacandona de Lancanhá. El manejo de los recursos suelo y vegetación realizado por las comunidades lacandonas y que consiste en el aprovechamiento forestal maderable y no maderable, además de la producción agrícola y pecuaria, ha permitido a los lacandones acumular un vasto conocimiento sobre la biología y utilidad de las especies nativas, lo cual se ha reflejado en la asignación de nombres comunes precisos y significativos a un gran número de ellas. Es así que los lacandones, único grupo humano realmente autóctono de la región, con un íntimo conocimiento tradicional sobre la flora y vegetación regionales, han desarrollado formas de aprovechamiento persistente mediante el sistema de roza, tumba y quema (Levy-Tacher et al., 2002). Este conocimiento tradicional podría servir para el enriquecimiento directo de los sistemas agrícolas actuales en la región como ha sido señalado en estudios previos, a través del estudio de las rutas sucesionales de comunidades vegetales bajo diferentes historiales de uso (Levy-Tacher y Golicher, 2004; Levy-Tacher y Aguirre-Rivera, 2005), y en última instancia a la rehabilitación ecológica de áreas agrícolas degradadas dentro de las tierras de selvas tropicales perennifolias (Levy-Tacher et al., 2012).

\section{Conclusiones}

La riqueza de especies de plantas vasculares registradas en las variantes de selva alta perennifolia y sus comunidades secundarias de la comunidad indígena de Nahá es notablemente alta en relación con su tamaño y es similar a la registrada en otras regiones dentro de la selva lacandona, lo cual coloca a estos relictos de selva en Chiapas como unos de los más diversos de México. El estado o condición de las variantes de vegetación madura estudiadas les confiere además importancia para su conservación. El conocimiento tradicional de los lacandones, único grupo humano realmente autóctono del área y en relación cultural directa con la flora y vegetación regionales, ha permitido la conservación de esta diversidad biológica dentro del área, a pesar de la constante presión de desarrollo que representan los poblados circundantes. De esta manera el presente estudio justifica de manera adicional el decreto de esta región como Área Natural Protegida.

\section{Agradecimientos}

El Consejo Nacional de Ciencia y Tecnología a través de una beca de posgrado otorgada a A. Durán permitió iniciar esta investigación; posteriormente, la Comisión Nacional para el Conocimiento y Uso de la Biodiversidad y Conservación Internacional México financiaron la labor de recolectas botánicas; a dos revisores anónimos que con sus valiosas observaciones y sugerencias contribuyeron a la mejora del manuscrito. Deseamos reconocer la participación de los lacandones de Nahá, quienes con su disposición para ayudarnos, guiarnos y cuidarnos, y sus conocimientos botánicos, hicieron posible la realización de este trabajo.

\section{Literatura citada}

Aguirre-Rrivera J.R. 1979. Metodología para el registro del conocimiento empírico de los campesinos en relación con el uso de recursos naturales renovables. Documento de Trabajo Núm. 3. CREZAS-Colegio de Postgraduados, Salinas de Hidalgo. 
APG [Angiosperm Phylogeny Group] III. 2009. An update of the Angiosperm Phylogeny Group classification for the orders and families of flowering plants: APG III. Botanical Journal of the Linnean Society 161:105-121.

Avila-Torresagatón L.G., Hidalgo-Mihart M. y Guerrero J.A. 2012. La importancia de Palenque, Chiapas, para la conservación de los murciélagos de México. Revista Mexicana de Biodiversidad 83:184-193.

Bongers F., Popma J., Meave-del Castillo J. y Carabias J. 1988. Structure and floristic composition of the lowland rain forest of Los Tuxtlas, Mexico. Vegetatio 74:55-80.

Breedlove D.E. 1981. Flora of Chiapas. Part 1: Introduction to the Flora of Chiapas. The California Academy of Sciences, San Francisco.

Breedlove D.E. 1986. Listados Florísticos de México IV. Flora de Chiapas. Instituto de Biología. Universidad Nacional Autónoma de México, México D.F.

Calzada J.I. y Valdivia P.E. 1979. Introducción al estudio de la vegetación de dos zonas de la selva Lacandona, Chiapas, México. Biótica 4:149-169.

Casco-Montoya R. 1984. Desarrollo rural integral de la selva Lacandona. Comisión del Plan Nacional Hidráulico, Secretaría de Agricultura y Recursos Hidráulicos, México D.F.

Castillo-Campos G. y Narave H. 1992. Contribución al conocimiento de la vegetación de la reserva de la Biósfera Montes Azules, Selva Lacandona, Chiapas, México. En: Vásquez-Sánchez M.A. y Ramos-Olmos M.A. Eds. Reserva de la Biósfera Montes Azules, Selva Lacandona: Investigación para su conservación, pp. 51-85, Publicaciones Especiales Ecosfera, A.C., San Cristóbal de las Casas.

Challenger A. y Soberón J. 2008. Los ecosistemas terrestres. En: Soberón J., Halffter G. y Llorente-Bousquets J. Comps. Capital Natural de México, vol. I: Conocimiento Actual de la Biodiversidad, pp. 87-108, Comisión nacional para el conocimiento y uso de la biodiversidad, México D.F.

Christenhusz M.J.M., Zhang X.-C. y Schneider H. 2011. A linear sequence of extant families and genera of lycophytes and ferns. Phytotaxa 19:7-54.

CONANP. 2006. Programa de Conservación y Manejo Área de Protección de Flora y Fauna Nahá. Comisión Nacional de Áreas Naturales Protegidas, México D.F.

Davidse G., Sousa M. y Chater A. Eds. 1994. Flora Mesoamericana. Alimestaceae a Cyperaceae. Vol. 6. Universidad Nacional Autónoma de México, Missouri Botanical Garden y The Natural History Museum (London), México D.F.

Davidse G., Sousa M. y Knapp S. Eds. 1995. Flora Mesoamericana. Psilotaceae a Salviniaceae. Vol. 1. Instituto de Biología, Universidad Nacional Autónoma de México, Missouri Botanical Garden y The Natural History Museum (London). México, D.F.

Ehrendorfer F. 1986. Geobotánica. En: Strasburger E., Noll F., Schenck H. y Schimper A.F.W. Eds. Tratado de Botánica, pp. 757-914, Marín, Barcelona.

Font Quer P. 1953. Diccionario de Botánica. Labor, Barcelona.

García E. 1973. Modificaciones al Sistema de Clasificación Climática de Köppen. Instituto de Geografía, Universidad Nacional Autónoma de México, México D.F.

García-Gil J.G. y Lugo-Hupb J. 1992. Las formas de relieve y los tipos de vegetación en la selva Lacandona. En: Vásquez-Sánchez M.A. y Ramos-Olmos M.A. Comps. Reserva de la Biósfera Montes Azules, Selva Lacandona: Investigación para su
Conservación. Publicaciones Especiales Ecosfera, A.C., pp 3949, San Cristóbal de las Casas.

Gentry A.H. 1990. Floristic similarities and differences between southern Central America and upper and Central Amazonia. En: Gentry A.W. Ed. Four Neotropical Rainforests, pp. 141-157, Yale University Press, New Haven.

Hubbell S.P. y Foster R.B. 1983. Diversity of canopy trees in a neotropical forest and implications for conservation. In: Sutton S.L., Whitmore T.C. y Chadwick A.C. Eds. Tropical Rain Forest: Ecology and Management, pp. 25-41, Blackwell.

INEGI. 1988a. Carta topográfica, E15, D74 (Las Margaritas), escala 1:50,000. Instituto Nacional de Estadística, Geografía e Informática, México D.F.

INEGI. 1988b Carta geológica, E15-12, D15-3 (Las Margaritas), escala 1:250,000. Instituto Nacional de Estadística, Geografía e Informática, México D.F.

INEGI. 1988c. Carta climática, E15-12, D15-3 (Las Margaritas), escala 1:250,000. Instituto Nacional de Estadística, Geografía e Informática, México D. F.

INEGI. 1988d. Carta de uso del suelo y vegetación, E15-12, D15-3 (Las Margaritas), escala 1:250,000. Instituto Nacional de Estadística, Geografía e Informática, México D.F.

INEGI. 2003. Conjunto de datos vectoriales de la carta de vegetación primaria 1:1,000,000. Instituto Nacional de Estadística, Geografía e Informática, Aguascalientes. http://www.inegi.org. $\mathrm{mx} / \mathrm{geo} /$ contenidos/recnat/usosuelo/inf_e1m.aspx

Levy-Tacher S.I., Aguirre-Rivera J.R., Martínez-Romero M.M. y Durán-Fernández A. 2002. Caracterización del uso tradicional de la flora espontánea en la comunidad Lacandona de Lacanhá, Chiapas, México. Interciencia 27:512-520.

Levy-Tacher S. y Golicher D. 2004. How predictive is traditional ecological knowledge? the case of the lacandon maya fallow enrichment system. Interciencia 29:496-502.

Levy-Tacher S.I. y Aguirre-Rivera J.R. 2005. Successional pathways derived from different vegetation use patterns by Lacandon Mayan indians. Journal of Sustainable Agriculture 26:49-82.

Levy-Tacher S., Aguirre-Rivera J.R., García-Perez J.D. y Martínez-Romero M.M. 2006. Aspectos florísticos de Lacanhá Chansayab, Selva Lacandona, Chiapas. Acta Botanica Mexicana 77:69-98.

Levy-Tacher S., Ramírez-Marcial N., González-Espinosa M. y Román-Dañobeytia F. 2012. Rehabilitación ecológica de áreas agropecuarias degradadas en la Selva Lacandona: una alternativa fincada en el conocimiento ecológico tradicional maya. En: Bello-Baltazar E., Naranjo-Piñera E.J. y Vandame R. Eds. La Otra Innovación para el Ambiente y la Sociedad en la Frontera Sur de México, pp. 248-258, El Colegio de la Frontera Sur y Red de Espacios de Innovación Socioambiental, San Cristóbal de las Casas .

Margalef R. 1974. Ecología. Omega, Barcelona.

Martínez E., Ramos C.H. y Chiang F. 1994. Lista florística de la Lacandona, Chiapas. Boletín de la Sociedad Botánica de México 54:99-177.

Meave-del Castillo J. (1990) Estructura y composición de la selva alta perennifolia de los alrededores de Bonampak. Instituto Nacional de Antropología e Historia/Consejo Nacional para la Cultura y las Artes, México. D.F.

Miranda F. 1952. La Vegetación de Chiapas, Primera Parte. Imprenta del Gobierno del Estado, Tuxtla Gutiérrez. 
Miranda F. 1953. La Vegetación de Chiapas, Segunda Parte. Imprenta del Gobierno del Estado, Tuxtla Gutiérrez.

Miranda F. 1961. Tres estudios botánicos en la Selva Lacandona, Chiapas. Boletín de la Sociedad Botánica de México 26:133176.

Miranda F. y Hernández-X. E. 1963. Los tipos de vegetación de México y su clasificación. Boletín de la Sociedad Botánica de México 28:29-179.

Muench-Navarro P.E.1978. Los sistemas de producción agrícola en la región Lacandona (Estudio agronómico preliminar). Tesis profesional. Universidad Autónoma Chapingo, Chapingo, Estado de México, México. 267 pp.

Müllerried F.K.G. 1957. Geología de Chiapas. Gobierno del Estado de Chiapas, Tuxtla Gutiérrez.

Nations J.D. y Nigh R.B. 1980. The evolutionary potential of Lacandon Maya sustained-yield tropical rain forest agriculture. Journal of Anthropological Research 36:1-30.

Odum E.P. 1985. Fundamentos de Ecología. Interamericana, México D.F.

Ricker M. y Daly D.C. 1998. Botánica Económica en Bosques Tropicales: Principios y Métodos para su Estudio y Aprovechamiento. Diana, México D.F.

Rzedowski J. 1978. Vegetación de México. Limusa, México D.F.

Rzedowski, J. 1993. Diversity and origins of the phanerogamic ora of Mexico. En: Ramamoorthy, T.P., Bye R., Lot A. y Fa J.. Eds. Biological diversity of Mexico: origins and distribution. Oxford University Press. Oxford, UK. pp. 129-144.[3]

Sarukhán-Kermez, J. 1968. Análisis sinecológico de las selvas de Terminalia amazonia. Tesis de Maestría, Escuela Nacional de Agricultura, Colegio de Postgraduados, Chapingo. 300 pp.

Toledo V.M. y Ordóñez M.J. 1998. El panorama de la biodiversidad de México: una revisión de los hábitats terrestres. En: Ramamoorthy T.P., Bye R, Lot A. y Fa J. Comps. Diversidad Biológica de México, Orígenes y Distribución, pp. 739-757, Instituto de Biología, Universidad Nacional Autónoma de México, México D.F.

Vásquez-Sánchez M.A. y Ramos-Olmos M.A. 1992. Reserva de la Biósfera Montes Azules, Selva Lacandona: Investigación para su Conservación. Publicaciones Especiales Ecosfera, A.C.. San Cristóbal de las Casas.

Vázquez-Torres M. 1989. Riqueza de plantas vasculares y la diversidad de especies arbóreas del dosel superior en 5 ha de selva tropical cálido-húmeda en la zona de Uxpanapa, Veracruz. Tesis de Maestría, Centro de Botánica, Colegio de Postgraduados, Chapingo, Estado de México, México. 294 pp.

Villaseñor J.L. 2004. Los géneros de plantas vasculares de la flora de México. Boletín de la Sociedad Botánica de México 75:105-135.

Recibido:10 de septiembre de 2014

Aceptado: 2 de diciembre de 2014 
Apéndice 1. Lista florística de la comunidad lacandona de Nahá, Chiapas, México. La lista está en orden alfabético por familia, género y especie. Las recolectas botánicas se realizaron entre noviembre de 1993 y mayo de 1995. Los nombres comunes en maya lacandón con los que se designan las especies son onomatopeyas. Las formas vitales fueron: árbol (Ar); arbusto (Ab); epífita (Ep); hemiepífita arbórea (Har); hemiepífita arbustiva (Hab); herbácea perenne (He); liana (Li); palma (Pa); parásita (Par); trepadora (Te). Las finalidades de uso reconocidas fueron: alimento para fauna (ALFA); alimento (ALIM); aromática (AROM); artesanal (ARTE); cera y miel (CEMI); ceremonial (CERE); cerco vivo (CEVI); chicle (CHIC); colorante (COLO); embarbascar (EMBA); envoltura (ENVO); fibra (FIBR); fuente de agua (FUAG); insecticida (INSE); instrumentos de trabajo (INTR); jabón (JABO); juguete (JUGE); leña (LEÑA); materiales para construcción (MACO); medicamento para animales (MEAN); medicinal (MEDI); ornamental (ORNA); resina (RESI); utensilios de uso doméstico (UTDO); venta (VENT); vestido (VEST). Los estratos fueron: I (herbáceo); II (arbustivo); III (arbóreo inferior); IV (arbóreo medio); V (arbóreo superior subdominante); VI (arbóreo superior dominante). La abundancia relativa tiene como límites: muy escaso (ME, menor que 1\%); escaso (E, entre 1 y $2.4 \%)$; poco abundante (PA, entre 2.5 y $5 \%$ ); abundante (A, entre 5.1 y $10 \%)$; muy abundante (MA, mayor que 10\%). Los hábitats de recolecta fueron selva alta perennifolia (SAP), plantas asociadas a la laguna (PAL), arvense y vegetación secundaria (AVS) y planta cultivada en palmar o solar (PCM).

\begin{tabular}{|c|c|c|c|c|c|c|c|}
\hline Clado/Familia/Especie & Recolecta & Nombre común & $\begin{array}{l}\text { Forma } \\
\text { vital }\end{array}$ & $\begin{array}{l}\text { Finalidad } \\
\text { de uso }\end{array}$ & Estrato & $\begin{array}{l}\text { Abundancia } \\
\text { relativa }\end{array}$ & Hábitat \\
\hline \multicolumn{8}{|l|}{ PTERIDOPHYTA } \\
\hline \multicolumn{8}{|l|}{ Aspleniaceae } \\
\hline Asplenium serra Langsd. \& Fisch. & A. Durán F. 558 & & Ep & & & & SAP \\
\hline \multicolumn{8}{|l|}{ Dryopteridaceae } \\
\hline Elaphoglossum obovatum Mickel. & $\begin{array}{l}\text { A. Durán F. } \\
555,559\end{array}$ & & $\mathrm{He}$ & & & & SAP \\
\hline \multicolumn{8}{|l|}{ Hymenophyllaceae } \\
\hline Hymenophyllum hirsutum (L.) Sw. & A. Durán F. 566 & & Ep & & & & SAP \\
\hline Trichomanes collariatum Bosch & A. Durán F. 225 & & $\mathrm{He}$ & & I & $\mathrm{E}$ & SAP \\
\hline \multicolumn{8}{|l|}{ Hypodematiaceae } \\
\hline $\begin{array}{l}\text { Didymochlaena truncatula } \\
\text { (Sw.) J. Sm. }\end{array}$ & $\begin{array}{l}\text { A. Durán F. 097, } \\
098\end{array}$ & & $\mathrm{He}$ & & 1 & $\mathrm{E}$ & SAP \\
\hline \multicolumn{8}{|l|}{ Lomariopsidaceae } \\
\hline Lomariopsis recurvata Fée & $\begin{array}{l}\text { A. Durán F. 570, } \\
571\end{array}$ & & Ep & & & & SAP \\
\hline \multicolumn{8}{|l|}{ Lycopodiaceae } \\
\hline $\begin{array}{l}\text { Huperzia taxifolia (Sw.) Trevis. } \\
\text { Polypodiaceae }\end{array}$ & \multicolumn{6}{|c|}{ Polypodiaceae } & PAL \\
\hline Campyloneurum xalapense Fée & A. Durán F. 326 & & Ep & & I & ME & SAP \\
\hline $\begin{array}{l}\text { Leucotrichum mitchelliae } \\
\text { (Baker) Labiak }\end{array}$ & A. Durán F. 569 & & Ep & & & & SAP \\
\hline $\begin{array}{l}\text { Pecluma atra (A.M. Evans) } \\
\text { M.G. Price }\end{array}$ & A. Durán F. 553 & & Ep & & & & SAP \\
\hline Pecluma sp. & A. Durán F. 314 & & Ep & & I & $\mathrm{E}$ & SAP \\
\hline Peltapteris peltata (Sw.) C.V. Morton & $\begin{array}{l}\text { A. Durán F. 555, } \\
559\end{array}$ & & Ep & & & A & SAP \\
\hline $\begin{array}{l}\text { Pleopeltis angusta Humb. \& } \\
\text { Bonpl. ex Willd. }\end{array}$ & A. Durán F. 618 & & Ep & & & & SAP \\
\hline $\begin{array}{l}\text { Polypodium eperopeutes Mickel } \\
\text { \& Beitel }\end{array}$ & A. Durán F. 315 & & Ep & & 1 & $\mathrm{E}$ & SAP \\
\hline \multicolumn{8}{|l|}{ Pteridaceae } \\
\hline Adiantum tenerum Sw. & $\begin{array}{l}\text { A. Durán F. 224, } \\
552\end{array}$ & Walkan wits & $\mathrm{He}$ & MEDI & 1 & PA & SAP \\
\hline $\begin{array}{l}\text { Adiantum tetraphyllum Humb. \& } \\
\text { Bonpl. ex Willd. }\end{array}$ & A. Durán F. 366 & Mesip ua ak & $\mathrm{He}$ & & 1 & PA & SAP \\
\hline \multicolumn{8}{|l|}{ Selaginellaceae } \\
\hline Selaginella martensii Spring & A. Durán F. 561 & & $\mathrm{He}$ & & & & SAP \\
\hline
\end{tabular}


Apéndice 1. Continuación

\begin{tabular}{|c|c|c|c|c|c|c|c|}
\hline Clado/Familia/Especie & Recolecta & Nombre común & $\begin{array}{l}\text { Forma } \\
\text { vital }\end{array}$ & $\begin{array}{l}\text { Finalidad } \\
\text { de uso }\end{array}$ & Estrato & $\begin{array}{l}\text { Abundancia } \\
\text { relativa }\end{array}$ & Hábitat \\
\hline \multicolumn{8}{|l|}{ Tectariaceae } \\
\hline $\begin{array}{l}\text { Tectaria heracleifolia (Willd.) } \\
\text { Underw. }\end{array}$ & A. Durán F. 562 & & $\mathrm{He}$ & & & & SAP \\
\hline \multicolumn{8}{|l|}{ Thelypteridaceae } \\
\hline $\begin{array}{l}\text { Christella dentata (Forssk.) } \\
\text { Brownsey \& Jermy }\end{array}$ & A. Durán F. 367 & & $\mathrm{He}$ & & I & $E$ & SAP \\
\hline $\begin{array}{l}\text { Macrothelypteris torresiana } \\
\text { (Gaudich.) Ching }\end{array}$ & A. Durán F. 209 & & $\mathrm{He}$ & & I & $\mathrm{E}$ & SAP \\
\hline \multicolumn{8}{|l|}{ GIMNOSPERMAE } \\
\hline \multicolumn{8}{|l|}{ Pinaceae } \\
\hline Pinus maximinoi H.E.Moore & $\begin{array}{l}\text { A. Durán F. 1096, } \\
1907\end{array}$ & & $\mathrm{Ar}$ & CERE & III & & SAP \\
\hline \multicolumn{8}{|l|}{ Podocarpaceae } \\
\hline Podocarpus matudae Lundell & A. Durán F. 324 & $\begin{array}{l}\text { Chibix xi wits, } \\
\text { A bedetate }\end{array}$ & $\mathrm{Ar}$ & ALFA, INTR & V & A & SAP \\
\hline \multicolumn{8}{|l|}{ ANGIOSPERMAE } \\
\hline \multicolumn{8}{|l|}{ MAGNÓLIDAS } \\
\hline \multicolumn{8}{|l|}{ Annonaceae } \\
\hline $\begin{array}{l}\text { Cymbopetalum penduliflorum } \\
\text { (Dunal) Baill. }\end{array}$ & $\begin{array}{l}\text { A. Durán F. 177, } \\
207\end{array}$ & Ton kuk & $\mathrm{Ar}$ & $\begin{array}{l}\text { MACO, } \\
\text { INTR, ALIM }\end{array}$ & IV & $\mathrm{E}$ & SAP \\
\hline Guatteria anomala R.E.Fr. & $\begin{array}{l}\text { A. Durán F. 176, } \\
208\end{array}$ & Ek bache & $\mathrm{Ar}$ & $\begin{array}{l}\text { MACO, } \\
\text { AROM }\end{array}$ & VI & A & SAP \\
\hline $\begin{array}{l}\text { Stenanona stenopetala (Donn.Sm.) } \\
\text { G.E.Schatz ex Maas, E.A. } \\
\text { Mennega \& Westra }\end{array}$ & A. Durán F. 061 & Opicax, Anona & $\mathrm{Ar}$ & & IV & ME & SAP \\
\hline \multicolumn{8}{|l|}{ Aristolochiaceae } \\
\hline \multicolumn{8}{|l|}{ Lauraceae } \\
\hline Licaria caudata (Lundell) Kosterm. & A. Durán F. 428 & Isa che & $\operatorname{Ar}$ & ARTE & III & $\mathrm{E}$ & SAP \\
\hline Licaria excelsa Kosterm. & A. Durán F. 407 & Sak onte & $\mathrm{Ar}$ & & IV & $\mathrm{E}$ & SAP \\
\hline Licaria peckii (I.M.Johnst.) Kosterm. & A. Durán F. 051 & Paquech ak & $\mathrm{Li}$ & LEÑA & IV & $\mathrm{E}$ & SAP \\
\hline Licaria triandra (Sw.) Kosterm. & A. Durán F. 1121 & Isa che & $\mathrm{Ar}$ & ALFA & III & & SAP \\
\hline Nectandra coriacea (Sw.) Griseb. & $\begin{array}{l}\text { A. Durán F. 356, } \\
\text { 423, } 606\end{array}$ & $\begin{array}{l}\text { Mejen onte, } \\
\text { Kaki che }\end{array}$ & $\mathrm{Ar}$ & ALFA & IV & ME & SAP \\
\hline $\begin{array}{l}\text { Nectandra membranacea (Sw.) } \\
\text { Griseb. }\end{array}$ & A. Durán F. 338 & $\begin{array}{l}\text { Tzonun che, } \\
\text { Mejen onte }\end{array}$ & $\mathrm{Ar}$ & $\begin{array}{l}\text { MACO, } \\
\text { LEÑA }\end{array}$ & V & ME & SAP \\
\hline Nectandra salicifolia (Kunth) Nees. & A. Durán F. 345 & Jo chok che & $\mathrm{Ar}$ & $\begin{array}{l}\text { MACO, } \\
\text { LEÑA }\end{array}$ & IV & $\mathrm{E}$ & SAP \\
\hline Ocotea cernua (Nees) Mez & A. Durán F. 432 & Mejen onte & $\mathrm{Ar}$ & & III & PA & SAP \\
\hline Ocotea sinuata (Mez) Rohwer & A. Durán F. 342 & Tza jak che & $\mathrm{Ar}$ & LEÑA, ALFA & IV & ME & SAP \\
\hline Persea liebmannii Mez & A. Durán F. 398 & Tzu naa che & $\mathrm{Ar}$ & & III & ME & SAP \\
\hline \multicolumn{8}{|l|}{ Magnoliaceae } \\
\hline Magnolia grandiflora L. & A. Durán F. 138 & Kutik & $\mathrm{Ar}$ & $\begin{array}{l}\text { LEÑA, } \\
\text { MACO, MEDI }\end{array}$ & VI & $\mathrm{E}$ & SAP \\
\hline Magnolia mexicana DC. & A. Durán F. 1144 & Kutik & $\mathrm{Ar}$ & MACO & IV & & SAP \\
\hline Magnolia pacifica Vazquez & A. Durán F. 1206 & & $\mathrm{Ar}$ & MACO & VI & $\mathrm{E}$ & SAP \\
\hline Magnolia schiedeana Schltl. & $\begin{array}{l}\text { A. Durán F. 212, } \\
258\end{array}$ & Che & $\mathrm{Ar}$ & & V & ME & SAP \\
\hline
\end{tabular}


Apéndice 1. Continuación

\begin{tabular}{|c|c|c|c|c|c|c|c|}
\hline Clado/Familia/Especie & Recolecta & Nombre común & $\begin{array}{l}\text { Forma } \\
\text { vital }\end{array}$ & $\begin{array}{l}\text { Finalidad } \\
\text { de uso }\end{array}$ & Estrato & $\begin{array}{l}\text { Abundancia } \\
\text { relativa }\end{array}$ & Hábitat \\
\hline \multicolumn{8}{|l|}{ Myristicaceae } \\
\hline $\begin{array}{l}\text { Compsoneura sprucei (A.DC.) } \\
\text { Warb. }\end{array}$ & $\begin{array}{l}\text { A. Durán F. 430, } \\
431\end{array}$ & $\begin{array}{l}\text { Sac onte, } \\
\text { Ek onte }\end{array}$ & $\mathrm{Ar}$ & & V & ME & SAP \\
\hline Virola guatemalensis (Hemsl.) Warb. & $\begin{array}{l}\text { A. Durán F. 032, } \\
221\end{array}$ & $\begin{array}{l}\text { Kiche, Majach, } \\
\text { Gik che }\end{array}$ & $\mathrm{Ar}$ & $\begin{array}{l}\text { ARTE, } \\
\text { MACO }\end{array}$ & $\mathrm{VI}$ & A & SAP \\
\hline \multicolumn{8}{|l|}{ Nymphaeaceae } \\
\hline $\begin{array}{l}\text { Nymphaea ampla (Salisb.) DC. } \\
\text { Piperaceae }\end{array}$ & A. Durán F. 575 & & $\mathrm{He}$ & & & & PAL \\
\hline Peperomia heterophylla Miq. & A. Durán F. 617 & & Ep & & & & SAP \\
\hline Peperomia obtusifolia (L.) A.Dietr. & $\begin{array}{l}\text { A. Durán F. 007, } \\
035\end{array}$ & & Ep & & & & SAP \\
\hline Peperomia quadrifolia (L.) Kunth & A. Durán F. 619 & & $\mathrm{He}$ & & & & SAP \\
\hline Piper auritum Kunth & A. Durán F. 584 & Jove & $\mathrm{Ab}$ & ENVO, ALIM & & & AVS \\
\hline Piper hispidum Sw. & $\begin{array}{l}\text { A. Durán F. 119, } \\
521\end{array}$ & $\begin{array}{l}\text { Makurum, } \\
\text { Jurtin che }\end{array}$ & $\mathrm{Ab}$ & MEDI & II & $\mathrm{E}$ & SAP \\
\hline Piper maxonii C.DC. & A. Durán F. 613 & Nukux makurum & $\mathrm{Ab}$ & & & & SAP \\
\hline \multicolumn{8}{|l|}{ Siparunaceae } \\
\hline $\begin{array}{l}\text { Siparuna thecaphora (Poepp. \& } \\
\text { Endl.) A.DC. }\end{array}$ & $\begin{array}{l}\text { A. Durán F. 027, } \\
086,519\end{array}$ & $\begin{array}{l}\text { Ya che kap, } \\
\text { Leulin che }\end{array}$ & $\mathrm{Ar}$ & CEMI & III & A & SAP \\
\hline \multicolumn{8}{|l|}{ MONOCOTILEDÓNEAS } \\
\hline \multicolumn{8}{|l|}{ Alismataceae } \\
\hline Sagittaria lancifolia L. & $\begin{array}{l}\text { A. Durán F. 589, } \\
602,1162\end{array}$ & $\begin{array}{l}\text { Uchucub xibi } \\
\text { petja }\end{array}$ & $\mathrm{He}$ & & I & & $\begin{array}{l}\text { SAP, } \\
\text { PAL }\end{array}$ \\
\hline \multicolumn{8}{|l|}{ Araceae } \\
\hline Anthurium scandens (Aubl.) Engl. & A. Durán F. 163 & & Ep & & & & SAP \\
\hline Monstera deliciosa Liebm. & $\begin{array}{l}\text { A. Durán F. 271, } \\
274,414\end{array}$ & $\begin{array}{l}\text { Camis irom, } \\
\text { Jach iram, Chup }\end{array}$ & $\mathrm{Te}$ & FIBR, ALIM & $\mathrm{V}$ & $\mathrm{E}$ & SAP \\
\hline Philodendron radiatum Schott & A. Durán F. 273 & A kix jub & Te & FIBR & II & $E$ & SAP \\
\hline Philodendron sagittifolium Liebm. & A. Durán F. 350 & Ochi iron & Te & FIBR & IV & ME & SAP \\
\hline Philodendron smithii Engl. & A. Durán F. 349 & Jorob & Te & $\begin{array}{l}\text { INTR, FIBR, } \\
\text { JABO }\end{array}$ & IV & $\mathrm{E}$ & SAP \\
\hline Philodendron standleyi Grayum & $\begin{array}{l}\text { A. Durán F. 266, } \\
388\end{array}$ & Ochi & Te & FIBR & V & ME & SAP \\
\hline Spathiphyllum phryniifolium Schott & A. Durán F. 083 & Poko & $\mathrm{He}$ & ALIM & I & PA & SAP \\
\hline Syngonium podophyllum Schott & $\begin{array}{l}\text { A. Durán F. 043, } \\
387,615\end{array}$ & Ochi & $\mathrm{Te}$ & & III & $\mathrm{E}$ & SAP \\
\hline \multicolumn{8}{|l|}{ Arecaceae } \\
\hline $\begin{array}{l}\text { Astrocaryum mexicanum Liebm. } \\
\text { ex Mart. }\end{array}$ & A. Durán F. 101 & Chapay, Akte & $\mathrm{Pa}$ & ALIM & II & $\mathrm{E}$ & SAP \\
\hline $\begin{array}{l}\text { Chamaedorea arenbergiana } \\
\text { H.Wendl. }\end{array}$ & $\begin{array}{l}\text { A. Durán F. 239, } \\
240,390\end{array}$ & Yax boy, Chip & $\mathrm{Pa}$ & CERE, ALIM & II & A & SAP \\
\hline Chamaedorea elegans Mart. & A. Durán F. 384 & Cambray & $\mathrm{Pa}$ & CERE, VENT & I & MA & SAP \\
\hline $\begin{array}{l}\text { Chamaedorea metallica O.F.Cook } \\
\text { ex H.E.Moore }\end{array}$ & A. Durán F. 245 & Kebe & $\mathrm{Pa}$ & ENVO, VENT & I & PA & SAP \\
\hline Chamaedorea oblongata Mart. & $\begin{array}{l}\text { A. Durán F. 047, } \\
389\end{array}$ & $\begin{array}{l}\text { Sac bori, } \\
\text { Kan boy }\end{array}$ & $\mathrm{Pa}$ & CERE, VENT & I & MA & SAP \\
\hline $\begin{array}{l}\text { Chamaedorea pinnatifrons } \\
\text { (Jacq.) Oerst. }\end{array}$ & A. Durán F. 244 & Xate & $\mathrm{Pa}$ & CERE & I & MA & SAP \\
\hline
\end{tabular}


Apéndice 1. Continuación

\begin{tabular}{|c|c|c|c|c|c|c|c|}
\hline Clado/Familia/Especie & Recolecta & Nombre común & $\begin{array}{l}\text { Forma } \\
\text { vital }\end{array}$ & $\begin{array}{l}\text { Finalidad } \\
\text { de uso }\end{array}$ & Estrato & $\begin{array}{l}\text { Abundancia } \\
\text { relativa }\end{array}$ & Hábitat \\
\hline $\begin{array}{l}\text { Cryosophila stauracantha (Heynh.) } \\
\text { R.J.Evans }\end{array}$ & A. Durán F. 247 & Kum & $\mathrm{Pa}$ & MACO, ALIM & II & A & SAP \\
\hline \multicolumn{8}{|l|}{ Asparagaceae } \\
\hline $\begin{array}{l}\text { Dracaena americana Donn.Sm. } \\
\text { Bromeliaceae }\end{array}$ & A. Durán F. 362 & A tzan & $\mathrm{Ar}$ & ALFA & IV & A & SAP \\
\hline $\begin{array}{l}\text { Aechmea lueddemanniana } \\
\text { (K.Koch) Mez }\end{array}$ & A. Durán F. 141 & & Ep & & & & SAP \\
\hline $\begin{array}{l}\text { Catopsis sessiliflora (Ruiz \& } \\
\text { Pav.) Mez }\end{array}$ & $\begin{array}{l}\text { A. Durán F. 009, } \\
\text { 096, } 243\end{array}$ & & Ep & & & & SAP \\
\hline Pitcairnia punicea Scheidw. & A. Durán F. 196 & & Ep & & & & SAP \\
\hline $\begin{array}{l}\text { Tillandsia festucoides Brongn. } \\
\text { ex Mez }\end{array}$ & $\begin{array}{l}\text { A. Durán F. 082, } \\
\text { 124, 125, 139, } 192\end{array}$ & & Ep & MEDI & & & SAP \\
\hline Tillandsia filifolia Schltdl. \& Cham. & $\begin{array}{l}\text { A. Durán F. 127, } \\
\text { 140, } 193\end{array}$ & & Ep & & & & SAP \\
\hline Tillandsia juncea (Ruiz \& Pav.) Poir. & $\begin{array}{l}\text { A. Durán F. 081, } \\
191\end{array}$ & & Ep & & & & SAP \\
\hline Tillandsia leiboldiana Schltdl. & $\begin{array}{l}\text { A. Durán F. 008, } \\
\text { 087, 095, 194, } 242\end{array}$ & & Ep & & & & SAP \\
\hline Tillandsia pruinosa Sw. & A. Durán F. 128 & & Ep & & & & SAP \\
\hline Tillandsia pseudobaileyi C.S.Gardner & A. Durán F. 126 & & Ep & & & & SAP \\
\hline Tillandsia sp. & A. Durán F. 195 & & Ep & & & & SAP \\
\hline $\begin{array}{l}\text { Tillandsia viridiflora (Beer) Baker } \\
\text { Commelinaceae }\end{array}$ & A. Durán F. 055 & & Ep & & & & SAP \\
\hline $\begin{array}{l}\text { Tradescantia zanonia (L.) Sw. } \\
\text { Costaceae }\end{array}$ & A. Durán F. 1337 & & $\mathrm{He}$ & & I & & SAP \\
\hline $\begin{array}{l}\text { Costus pulverulentus C.Presl } \\
\text { Cyclanthaceae }\end{array}$ & A. Durán F. 042 & Pasai & $\mathrm{He}$ & & I & $\mathrm{E}$ & SAP \\
\hline $\begin{array}{l}\text { Asplundia labela (R.E.Schult.) Harling } \\
\text { Cyperaceae }\end{array}$ & A. Durán F. 157 & Nekambor & Ep & & I & PA & SAP \\
\hline $\begin{array}{l}\text { Eleocharis interstincta (Vahl) Roem. } \\
\text { \& Schult. }\end{array}$ & A. Durán F. 591 & Tziril & $\mathrm{He}$ & UTDO & & & PAL \\
\hline $\begin{array}{l}\text { Rhynchospora holoschoenoides } \\
\text { (Rich.) Herter }\end{array}$ & A. Durán F. 1298 & Sukija & $\mathrm{He}$ & & I & A & SAP \\
\hline $\begin{array}{l}\text { Rhynchospora radicans (Schltdl. } \\
\text { \& Cham.) H.Pfeiff. }\end{array}$ & A. Durán F. 529 & & $\mathrm{He}$ & & & & AVS \\
\hline Dioscoreaceae & & & & & & & \\
\hline $\begin{array}{l}\text { Dioscorea composita Hemsl. } \\
\text { Heliconiaceae }\end{array}$ & A. Durán F. 631 & Kurak & $\mathrm{Te}$ & & & & AVS \\
\hline $\begin{array}{l}\text { Heliconia librata Griggs } \\
\text { Iridaceae }\end{array}$ & A. Durán F. 351 & Chu kux xibi & $\mathrm{He}$ & ENVO & II & PA & SAP \\
\hline $\begin{array}{l}\text { Neomarica gracilis (Herb.) Sprague } \\
\text { Marantaceae }\end{array}$ & A. Durán F. 077 & pasto & $\mathrm{He}$ & & I & $\mathrm{E}$ & SAP \\
\hline $\begin{array}{l}\text { Calathea microcephala (Poepp. \& } \\
\text { Endl.) Körn. }\end{array}$ & A. Durán F. 707 & & $\mathrm{He}$ & & & & SAP \\
\hline Maranta gibba Sm. & $\begin{array}{l}\text { A. Durán F. 044, } \\
093\end{array}$ & Aki xibi, Te usir & $\mathrm{He}$ & ENVO & I & $A$ & SAP \\
\hline Orchidaceae & & & & & & & \\
\hline $\begin{array}{l}\text { Arpophyllum giganteum Hartw. } \\
\text { ex Lindl. }\end{array}$ & A. Durán F. 313 & Tziran & Ep & ORNA & & & SAP \\
\hline
\end{tabular}


Apéndice 1. Continuación

\begin{tabular}{|c|c|c|c|c|c|c|c|}
\hline Clado/Familia/Especie & Recolecta & Nombre común & $\begin{array}{l}\text { Forma } \\
\text { vital }\end{array}$ & $\begin{array}{l}\text { Finalidad } \\
\text { de uso }\end{array}$ & Estrato & $\begin{array}{l}\text { Abundancia } \\
\text { relativa }\end{array}$ & Hábitat \\
\hline $\begin{array}{l}\text { Calanthe calanthoides (A.Rich. \& } \\
\text { Galeotti) Hamer \& Garay }\end{array}$ & A. Durán F. 734 & & Ep & & & & SAP \\
\hline $\begin{array}{l}\text { Camaridium cucullatum (Lindl.) } \\
\text { M.A.Blanco }\end{array}$ & A. Durán F. 508 & Chac k'och bats & Ep & & & & SAP \\
\hline $\begin{array}{l}\text { Camaridium meleagris (Lindl.) } \\
\text { M.A.Blanco }\end{array}$ & A. Durán F. 014 & & Ep & & & & SAP \\
\hline Camaridium pulchrum Schltr. & $\begin{array}{l}\text { A. Durán F. 184, } \\
363\end{array}$ & & Ep & & & & SAP \\
\hline $\begin{array}{l}\text { Dichaea muricatoides Hamer } \\
\text { \& Garay }\end{array}$ & A. Durán F. 620 & & Ep & & & & SAP \\
\hline $\begin{array}{l}\text { Epidendrum abbottii L.Sánchez } \\
\text { \& Hágsater }\end{array}$ & $\begin{array}{l}\text { A. Durán F. 651, } \\
720\end{array}$ & & Ep & ORNA & & & SAP \\
\hline Epidendrum atroscriptum Hágsater & A. Durán F. 197 & & Ep & & & & SAP \\
\hline Epidendrum flexuosum G.Mey. & A. Durán F. 1179 & & Ep & & & $A$ & SAP \\
\hline Epidendrum nocturnum Jacq. & A. Durán F. 687 & & Ep & & & & SAP \\
\hline Epidendrum polyanthum Lindl. & A. Durán F. 376 & & Ep & & & & SAP \\
\hline Epidendrum radicans Pav. ex Lindl. & A. Durán F. 668 & & Ep & & & & SAP \\
\hline Epidendrum ramosum Jacq. & A. Durán F. 237 & & Ep & & & & SAP \\
\hline Epidendrum santaclarense Ames & A. Durán F. 588 & Ochi & Ep & & & & SAP \\
\hline $\begin{array}{l}\text { Erycina pusilla (L.) N.H.Williams } \\
\quad \text { \& M.W.Chase }\end{array}$ & $\begin{array}{l}\text { A. Durán F. 525, } \\
589\end{array}$ & $\begin{array}{l}\text { Maja co'ox bats } \\
\text { acan utop }\end{array}$ & Ep & ORNA & & & SAP \\
\hline Habenaria pringlei B.L.Rob. & A. Durán F. 577 & & $\mathrm{He}$ & & & & PAL \\
\hline Isochilus carnosiflorus Lindl. & A. Durán F. 060 & & Ep & & & & SAP \\
\hline $\begin{array}{l}\text { Jacquiniella equitantifolia (Ames) } \\
\text { Dressler }\end{array}$ & $\begin{array}{l}\text { A. Durán F. 011, } \\
088\end{array}$ & & Ep & & & & SAP \\
\hline Lockhartia oerstedii Rchb.f. & $\begin{array}{l}\text { A. Durán F. 010, } \\
686\end{array}$ & & Ep & & II & & SAP \\
\hline Lycaste aff. cochleata Lindl. & A. Durán F. 592 & & Ep & & & & SAP \\
\hline Lycaste bradeorum Schltr. & $\begin{array}{l}\text { A. Durán F. 178, } \\
246,1207\end{array}$ & Koch batz & Ep & & & & SAP \\
\hline $\begin{array}{l}\text { Maxillariella anceps (Ames \& C. } \\
\text { Schweinf.) M.A.Blanco \& Carnevali }\end{array}$ & A. Durán F. 509 & Sibi che & Ep & & & & SAP \\
\hline $\begin{array}{c}\text { Maxillariella variabilis (Bateman ex } \\
\text { Lindl.) M.A.Blanco \& Carnevali }\end{array}$ & $\begin{array}{l}\text { A. Durán F. 012, } \\
013\end{array}$ & & Ep & & & & SAP \\
\hline Mormodes nagelii L.O.Williams & $\begin{array}{l}\text { A. Durán F. 624, } \\
722\end{array}$ & & Ep & MEDI & & & AVS \\
\hline Nidema boothii (Lindl.) Schltr. & A. Durán F. 685 & & Ep & ORNA & & & SAP \\
\hline $\begin{array}{l}\text { Platystele stenostachya (Rchb.f.) } \\
\text { Garay }\end{array}$ & A. Durán F. 621 & & Ep & & & & SAP \\
\hline Pleurothallis bivalvis Lindl. & A. Durán F. 579 & & Ep & & & & SAP \\
\hline Polystachya foliosa (Hook.) Rchb.f. & A. Durán F. 750 & & Ep & & & & SAP \\
\hline $\begin{array}{l}\text { Prosthechea cochleata (L.) } \\
\text { W.E.Higgins }\end{array}$ & $\begin{array}{l}\text { A. Durán F. 015, } \\
238\end{array}$ & & Ep & $\mathrm{JABO}$ & & & SAP \\
\hline $\begin{array}{l}\text { Prosthechea neurosa (Ames) } \\
\text { W.E.Higgins }\end{array}$ & $\begin{array}{l}\text { A. Durán F. 041, } \\
070\end{array}$ & & Ep & & & & SAP \\
\hline $\begin{array}{l}\text { Prosthechea radiata (Lindl.) } \\
\text { W. E. Higgins }\end{array}$ & A. Durán F. 069 & & Ep & ORNA & & & SAP \\
\hline $\begin{array}{l}\text { Rhetinantha aciantha (Rchb.f.) } \\
\text { M.A.Blanco }\end{array}$ & A. Durán F. 080 & & Ep & & & & SAP \\
\hline
\end{tabular}


Apéndice 1. Continuación

\begin{tabular}{|c|c|c|c|c|c|c|c|}
\hline Clado/Familia/Especie & Recolecta & Nombre común & $\begin{array}{l}\text { Forma } \\
\text { vital }\end{array}$ & $\begin{array}{l}\text { Finalidad } \\
\text { de uso }\end{array}$ & Estrato & $\begin{array}{l}\text { Abundancia } \\
\text { relativa }\end{array}$ & Hábitat \\
\hline Sobralia decora Bateman & A. Durán F. 079 & & Ep & & & & SAP \\
\hline $\begin{array}{l}\text { Specklinia brighamii (S.Watson) } \\
\text { Pridgeon \& M.W.Chase }\end{array}$ & $\begin{array}{l}\text { A. Durán F. 580, } \\
581\end{array}$ & & Ep & & & & SAP \\
\hline $\begin{array}{l}\text { Stelis immersa (Linden \& Rchb.f.) } \\
\quad \text { Pridgeon \& M.W.Chase }\end{array}$ & A. Durán F. 510 & & Ep & & & & SAP \\
\hline Stelis sp. & A. Durán F. 684 & & Ep & & & & SAP \\
\hline Vanilla planifolia Jacks. ex Andrews & A. Durán F. 1166 & & $\mathrm{Te}$ & AROM & III & & SAP \\
\hline $\begin{array}{l}\text { Vanilla sp. } \\
\text { Poaceae }\end{array}$ & A. Durán F. 110 & Vainilla, Buclux & $\mathrm{Te}$ & AROM & III & ME & SAP \\
\hline $\begin{array}{l}\text { Andropogon glomeratus (Walter) } \\
\text { Britton, Sterns \& Poggenb. }\end{array}$ & A. Durán F. 1278 & Ujara kisin & $\mathrm{He}$ & & 1 & A & SAP \\
\hline Andropogon virginicus L. & A. Durán F. 1318 & Jarasuk & $\mathrm{He}$ & & 1 & A & SAP \\
\hline Arundinella deppeana Nees & A. Durán F. 1322 & Sac suk & $\mathrm{He}$ & & 1 & A & AVS \\
\hline Coix lacryma-jobi L. & A. Durán F. s/n & Nikan & $\mathrm{He}$ & ARTE & & & AVS \\
\hline $\begin{array}{l}\text { Cynodon plectostachyus (K. } \\
\text { Schum.) Pilg. }\end{array}$ & A. Durán F. 1305 & & $\mathrm{He}$ & & II & A & SAP \\
\hline Gynerium sagittatum (Aubl.) P.Beauv. & A. Durán F. 719 & Ho, Carrizo & $\mathrm{He}$ & ARTE & & & PCM \\
\hline $\begin{array}{l}\text { Imperata contracta (Humb., Bonpl. } \\
\text { \& Kunth) Hitchc. }\end{array}$ & A. Durán F. 1285 & Ak zuk & $\mathrm{He}$ & & 1 & A & SAP \\
\hline $\begin{array}{l}\text { Lasiacis procerrima (Hack.) Hitchc. } \\
\text { ex Chase }\end{array}$ & A. Durán F. 711 & & $\mathrm{He}$ & & & & AVS \\
\hline Olyra latifolia L. & A. Durán F. 130 & Sit & $\mathrm{He}$ & & 1 & PA & SAP \\
\hline Panicum hirsutum Sw. & A. Durán F. 1311 & Xas suj & $\mathrm{He}$ & & I & $A$ & SAP \\
\hline Paspalum affine Steud. & A. Durán F. 1270 & Zajap suk & $\mathrm{He}$ & & I & A & AVS \\
\hline Paspalum conjugatum P.J.Bergius & A. Durán F. 1362 & & $\mathrm{He}$ & & I & A & SAP \\
\hline Paspalum plicatulum Michx. & A. Durán F. 1294 & Sac suk & $\mathrm{He}$ & & II & A & AVS \\
\hline Paspalum virgatum $\mathrm{L}$. & $\begin{array}{l}\text { A. Durán F. 1271, } \\
\text { 1296, } 1314\end{array}$ & $\begin{array}{l}\text { Nuk sok, } \\
\text { Nukusuk, } \\
\text { Nucusuca }\end{array}$ & $\mathrm{He}$ & & II & A & AVS \\
\hline Pennisetum polystachion (L.) Schult. & A. Durán F. 1348 & Ovisuk & $\mathrm{He}$ & & II & A & AVS \\
\hline Setaria parviflora (Poir.) Kerguelen & A. Durán F. 1299 & Majan suk & $\mathrm{He}$ & & 1 & & AVS \\
\hline $\begin{array}{l}\text { Sporobolus indicus (L.) R.Br. } \\
\text { Pontederiaceae }\end{array}$ & A. Durán F. 1327 & Ak suk & $\mathrm{He}$ & & I & & SAP \\
\hline $\begin{array}{l}\text { Pontederia sagittata C.Presl } \\
\text { Potamogetonaceae }\end{array}$ & A. Durán F. 576 & & $\mathrm{He}$ & & & & PAL \\
\hline $\begin{array}{l}\text { Potamogeton illinoensis Morong } \\
\text { Smilacaceae }\end{array}$ & A. Durán F. 539 & & $\mathrm{He}$ & & & & PAL \\
\hline $\begin{array}{l}\text { Smilax domingensis Willd. } \\
\text { Triuridaceae }\end{array}$ & A. Durán F. 622 & Suki ak & $\mathrm{Te}$ & & & & AVS \\
\hline $\begin{array}{l}\text { Triuris brevistylis Donn.Sm. } \\
\text { Zingiberaceae }\end{array}$ & A. Durán F. s/n & Kuxulum & Sa & & & & SAP \\
\hline $\begin{array}{l}\text { Renealmia mexicana Klotzsch } \\
\text { ex Petersen }\end{array}$ & A. Durán F. 265 & & $\mathrm{He}$ & & 1 & ME & SAP \\
\hline $\begin{array}{l}\text { EUDICOTILEDÓNEAS } \\
\text { Acanthaceae }\end{array}$ & & & & & & & \\
\hline Justicia borrerae (Hemsl.) T.F. Daniel & A. Durán F. 262 & & $\mathrm{Ab}$ & & II & PA & SAP \\
\hline $\begin{array}{l}\text { Justicia fimbriata (Nees) V.A.W. } \\
\text { Graham }\end{array}$ & A. Durán F. 073 & Kan top che & $\mathrm{Ar}$ & & II & PA & SAP \\
\hline
\end{tabular}


Apéndice 1. Continuación

\begin{tabular}{|c|c|c|c|c|c|c|c|}
\hline Clado/Familia/Especie & Recolecta & Nombre común & $\begin{array}{l}\text { Forma } \\
\text { vital }\end{array}$ & $\begin{array}{l}\text { Finalidad } \\
\text { de uso }\end{array}$ & Estrato & $\begin{array}{l}\text { Abundancia } \\
\text { relativa }\end{array}$ & Hábitat \\
\hline Justicia spicigera Schltdl. & A. Durán F. 1159 & Tzits & $\mathrm{Te}$ & ARTE & III & & SAP \\
\hline $\begin{array}{l}\text { Odontonema callistachyum (Schltdl. } \\
\text { \& Cham.) Kuntze }\end{array}$ & A. Durán F. 514 & Curan che & $\mathrm{Ab}$ & & & & SAP \\
\hline \multicolumn{8}{|l|}{ Actinidiaceae } \\
\hline Saurauia leucocarpa Schltdl. & A. Durán F. 690 & & $\mathrm{Ar}$ & & & & AVS \\
\hline Saurauia rubiformis Vatke & A. Durán F. 1261 & $\begin{array}{l}\text { Chei chaca } \\
\text { withs }\end{array}$ & $\operatorname{Ar}$ & & III & & SAP \\
\hline Saurauia scabrida Hemsl. & A. Durán F. 078 & Jop te che & $\mathrm{Ar}$ & CEMI, LEÑA & IV & PA & SAP \\
\hline Saurauia selerorum Buscal. & A. Durán F. 502 & Woron che & $\mathrm{Ar}$ & & & & SAP \\
\hline \multicolumn{8}{|l|}{ Adoxaceae } \\
\hline Sambucus canadensis L. & A. Durán F. 672 & Choris che & $\mathrm{Ar}$ & MEDI & & & PCM \\
\hline \multicolumn{8}{|l|}{ Amaranthaceae } \\
\hline Amaranthus hybridus L. & A. Durán F. 546 & & $\mathrm{He}$ & ALIM & & & AVS \\
\hline $\begin{array}{l}\text { Iresine diffusa Humb. \& Bonpl. } \\
\text { ex Willd. }\end{array}$ & A. Durán F. 680 & Axana lobí & $\mathrm{He}$ & & & & AVS \\
\hline \multicolumn{8}{|l|}{ Anacardiaceae } \\
\hline $\begin{array}{l}\text { Mosquitoxylum jamaicense } \\
\text { Krug \& Urb. }\end{array}$ & A. Durán F. 092 & Nukux kan or & $\mathrm{Ar}$ & MACO, CEMI & V & $\mathrm{E}$ & SAP \\
\hline \multicolumn{8}{|l|}{ Apiaceae } \\
\hline & \multicolumn{3}{|c|}{ Apocynaceae } & MEDI & II & & SAP \\
\hline Asclepias curassavica L. & A. Durán F. 671 & Tzac chiua ko & $\mathrm{He}$ & MEDI & & & AVS \\
\hline $\begin{array}{l}\text { Aspidosperma megalocarpon } \\
\text { Müll.Arg. }\end{array}$ & A. Durán F. 379 & A sa yok che & $\mathrm{Ar}$ & MACO, INSE & V & $\mathrm{PA}$ & SAP \\
\hline $\begin{array}{l}\text { Mandevilla subsagittata (Ruiz \& } \\
\text { Pav.) Woodson }\end{array}$ & A. Durán F. 733 & & $\mathrm{Te}$ & & & & AVS \\
\hline $\begin{array}{l}\text { Metalepis peraffinis (Woodson) } \\
\text { Morillo }\end{array}$ & A. Durán F. 1356 & & $\mathrm{He}$ & & III & $A$ & SAP \\
\hline $\begin{array}{l}\text { Prestonia portobellensis (Beurl.) } \\
\text { Woodson }\end{array}$ & A. Durán F. 726 & & Te & & & & AVS \\
\hline Tabernaemontana alba Mill. & A. Durán F. 515 & Pak'a che & $\mathrm{Ar}$ & & III & & SAP \\
\hline Tassadia obovata Decne. & A. Durán F. 716 & & $\mathrm{Te}$ & & & & AVS \\
\hline Thevetia ahouai (L.) A.DC. & $\begin{array}{l}\text { A. Durán F. 031, } \\
136\end{array}$ & Tuch & $\mathrm{Ar}$ & $\begin{array}{l}\text { ORNA, ALIM, } \\
\text { MEDI }\end{array}$ & II & $\mathrm{ME}$ & SAP \\
\hline $\begin{array}{l}\text { Tonduzia longifolia (A.DC.) Markgr. } \\
\text { Aquifoliaceae }\end{array}$ & A. Durán F. 370 & Tzid tia & $\mathrm{Ar}$ & & IV & ME & SAP \\
\hline Ilex costaricensis Donn.Sm. & $\begin{array}{l}\text { A. Durán F. 180, } \\
354\end{array}$ & $\begin{array}{l}\text { Bayan che, } \\
\text { Yan che kap }\end{array}$ & $\mathrm{Ar}$ & LEÑA & IV & $\mathrm{E}$ & SAP \\
\hline \multicolumn{8}{|l|}{ Araliaceae } \\
\hline $\begin{array}{l}\text { Dendropanax arboreus (L.) } \\
\text { Decne. \& Planch. }\end{array}$ & $\begin{array}{l}\text { A. Durán F. 059, } \\
206,211,393\end{array}$ & $\begin{array}{l}\text { Saja jak che, } \\
\text { Sac sac che, } \\
\text { Jeke che }\end{array}$ & $\mathrm{Ar}$ & $\begin{array}{l}\text { MEDI, } \\
\text { MACO, LEÑA, } \\
\text { CEMI }\end{array}$ & V & ME & SAP \\
\hline Oreopanax geminatus Marchal & A. Durán F. s/n & & $\mathrm{Ar}$ & & & & SAP \\
\hline $\begin{array}{l}\text { Oreopanax guatemalensis (Lem. } \\
\text { ex Bosse) Decne. \& Planch. }\end{array}$ & A. Durán F. 412 & Kaa ta kin che & Har & & IV & ME & SAP \\
\hline Oreopanax peltatus Linden ex Regel & A. Durán F. 1095 & & $\mathrm{Ar}$ & MACO & III & & SAP \\
\hline
\end{tabular}


Apéndice 1. Continuación

\begin{tabular}{|c|c|c|c|c|c|c|c|}
\hline Clado/Familia/Especie & Recolecta & Nombre común & $\begin{array}{l}\text { Forma } \\
\text { vital }\end{array}$ & $\begin{array}{l}\text { Finalidad } \\
\text { de uso }\end{array}$ & Estrato & $\begin{array}{l}\text { Abundancia } \\
\text { relativa }\end{array}$ & Hábitat \\
\hline \multicolumn{8}{|l|}{ Asteraceae } \\
\hline $\begin{array}{l}\text { Ageratina ligustrina (DC.) R.M.King } \\
\text { \& H.Rob. }\end{array}$ & A. Durán F. 039 & Che & $\mathrm{Ab}$ & & II & PA & SAP \\
\hline Bidens odorata Cav. & A. Durán F. 530 & & $\mathrm{He}$ & & & & AVS \\
\hline Calea integrifolia (DC.) Hemsl. & A. Durán F. 444 & Kusi ak & $\mathrm{Li}$ & & & & SAP \\
\hline Calea oliveri B.L.Rob. \& Greenm. & A. Durán F. 709 & Tza tza ak & $\mathrm{Li}$ & & & & SAP \\
\hline Chaptalia nutans (L.) Polák & A. Durán F. 604 & Tzak tzuku chi & $\mathrm{He}$ & & I & A & AVS \\
\hline $\begin{array}{l}\text { Chromolaena collina (DC.) R.M. } \\
\text { King \& H.Rob. }\end{array}$ & A. Durán F. 451 & Sisi lobí & $\mathrm{He}$ & & I & A & SAP \\
\hline Cirsium mexicanum DC. & $\begin{array}{l}\text { A. Durán F. 544, } \\
603\end{array}$ & Tzak zuk chi & $\mathrm{He}$ & MEDI & & & AVS \\
\hline Clibadium arboreum Donn.Sm. & A. Durán F. 663 & Kibo che & $\mathrm{Ab}$ & & & & AVS \\
\hline Erigeron canadensis L. & $\begin{array}{l}\text { A. Durán F. 691, } \\
1324\end{array}$ & $\begin{array}{l}\text { Sisin kusi lobí, } \\
\text { sisi lobi }\end{array}$ & $\mathrm{He}$ & & II & A & AVS \\
\hline Eupatorium sp. & A. Durán F. 001 & Sac chei chaca & $\operatorname{Ar}$ & & II & $\mathrm{E}$ & SAP \\
\hline $\begin{array}{l}\text { Fleischmannia pycnocephala (Less.) } \\
\text { R.M.King \& H.Rob. }\end{array}$ & A. Durán F. 643 & Sisi lobí & $\mathrm{He}$ & & I & A & AVS \\
\hline Hebeclinium macrophyllum (L.) DC. & A. Durán F. 1336 & sisikus & $\mathrm{He}$ & & II & A & SAP \\
\hline $\begin{array}{l}\text { Koanophyllon galeottii (B.L.Rob.) } \\
\text { R.M.King \& H.Rob. }\end{array}$ & A. Durán F. 522 & K'ak'a che & $\mathrm{Ab}$ & & & & SAP \\
\hline Lasianthaea fruticosa (L.) K.M.Becker & A. Durán F. 459 & Chak jaro che & $\mathrm{Ar}$ & MEDI & & & SAP \\
\hline Mikania hookeriana DC. & A. Durán F. 268 & & $\mathrm{Te}$ & & II & ME & SAP \\
\hline Mikania micrantha Kunth & A. Durán F. 447 & Kasi che & Ar & & & & SAP \\
\hline Mikania pterocaula Sch.Bip. ex Klatt & A. Durán F. 1216 & Mejen yax chak & $\mathrm{Te}$ & & V & & SAP \\
\hline Neurolaena lobata (L.) R.Br. ex Cass. & A. Durán F. 455 & Siskej & $\mathrm{Ab}$ & & & & SAP \\
\hline Parthenium hysterophorus L. & A. Durán F. 1355 & Kaka lobi & $\mathrm{He}$ & & I & A & AVS \\
\hline $\begin{array}{l}\text { Peteravenia schultzii (Schnittsp.) } \\
\text { R.M.King \& H.Rob. }\end{array}$ & A. Durán F. 501 & Sak'i lobí & $\mathrm{Ab}$ & & II & & SAP \\
\hline Pluchea carolinensis (Jacq.) D.Don & A. Durán F. 456 & & $\operatorname{Ar}$ & & III & $A$ & AVS \\
\hline $\begin{array}{l}\text { Schistocarpha eupatorioides } \\
\text { (Fenzl) Kuntze }\end{array}$ & $\begin{array}{l}\text { A. Durán F. 722, } \\
443\end{array}$ & $\begin{array}{l}\text { Sisi lobí/ A } \\
\text { sukí lobí }\end{array}$ & $\mathrm{He}$ & & & & AVS \\
\hline Sinclairia deppeana (Less.) Rydb. & A. Durán F. 353 & Kan sum & $\mathrm{Hab}$ & & II & ME & SAP \\
\hline Sonchus oleraceus (L.) L. & A. Durán F. 540 & & $\mathrm{He}$ & & & & AVS \\
\hline $\begin{array}{l}\text { Telanthophora grandifolia (Less.) } \\
\text { H.Rob. \& Brettell }\end{array}$ & A. Durán F. 169 & Baron che & $\mathrm{Ar}$ & & II & PA & SAP \\
\hline $\begin{array}{l}\text { Verbesina chiapensis B.L.Rob. } \\
\text { \& Greenm. }\end{array}$ & A. Durán F. 735 & & $\mathrm{He}$ & & & & AVS \\
\hline $\begin{array}{l}\text { Verbesina lanata B.L.Rob. \& Greenm. } \\
\text { Begoniaceae }\end{array}$ & A. Durán F. 252 & Che & $\mathrm{Ar}$ & & II & PA & SAP \\
\hline Begonia fischeri Schrank & A. Durán F. 590 & & $\mathrm{He}$ & & & & PAL \\
\hline Begonia glabra Aubl. & A. Durán F. 328 & A takan de ak & $\mathrm{Te}$ & & II & $\mathrm{E}$ & SAP \\
\hline $\begin{array}{l}\text { Begonia nelumbiifolia Cham. } \\
\text { \& Schltdl. }\end{array}$ & A. Durán F. 578 & & $\mathrm{He}$ & & & & AVS \\
\hline \multicolumn{8}{|l|}{ Bignoniaceae } \\
\hline Amphitecna silvicola L.O.Williams & $\begin{array}{l}\text { A. Durán F. 261, } \\
306\end{array}$ & Luch mon & $\mathrm{Ar}$ & ALFA & IV & ME & SAP \\
\hline $\begin{array}{l}\text { Callichlamys latifolia (Rich.) } \\
\text { K. Schum. }\end{array}$ & A. Durán F. 1160 & Nukuch xak ak & $\mathrm{Te}$ & ALIM & V & & SAP \\
\hline $\begin{array}{l}\text { Fridericia chica (Bonpl.) L.G. } \\
\text { Lohmann }\end{array}$ & A. Durán F. 652 & & $\mathrm{Li}$ & & & & AVS \\
\hline
\end{tabular}


Apéndice 1. Continuación

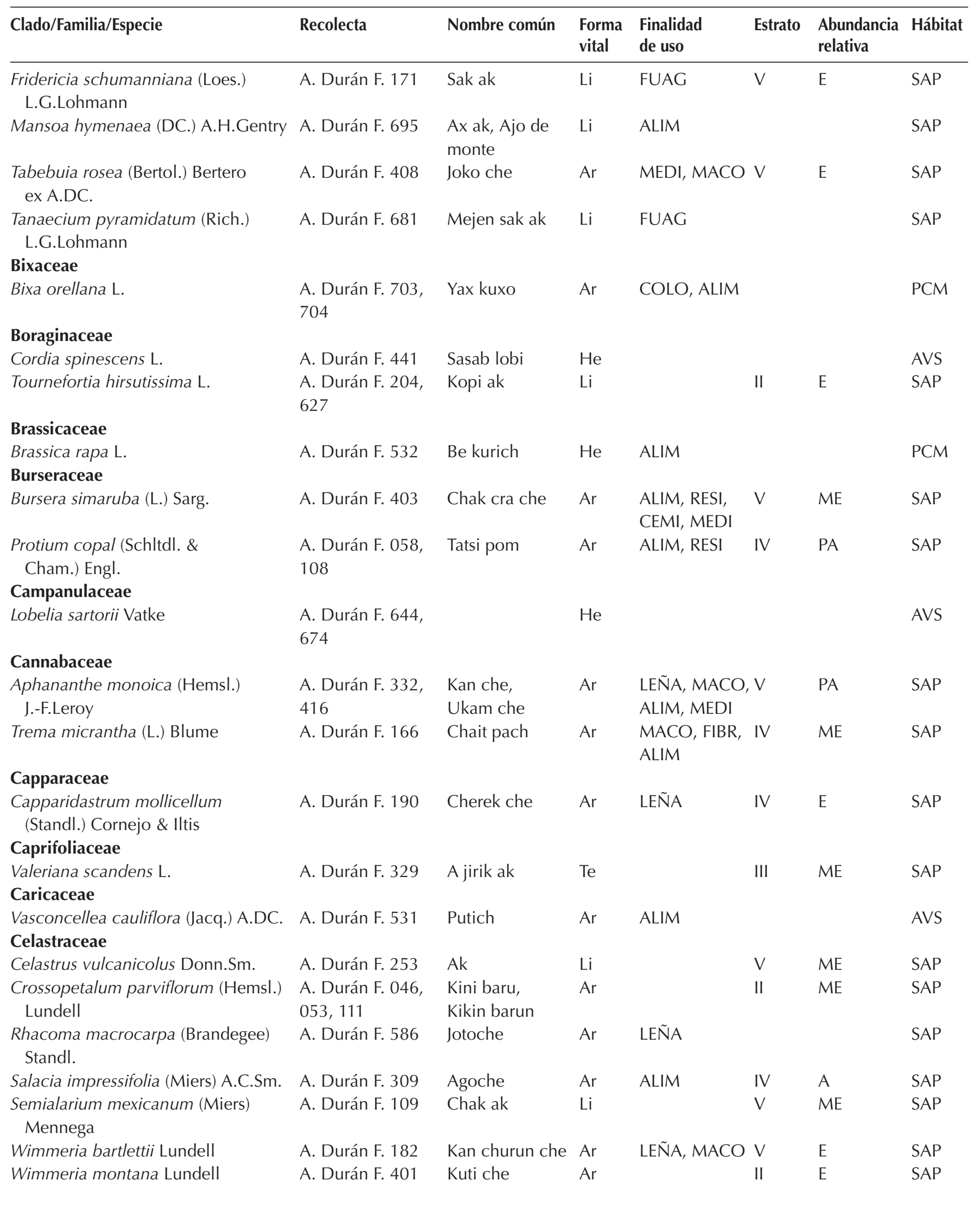


Apéndice 1. Continuación

\begin{tabular}{|c|c|c|c|c|c|c|c|}
\hline Clado/Familia/Especie & Recolecta & Nombre común & $\begin{array}{l}\text { Forma } \\
\text { vital }\end{array}$ & $\begin{array}{l}\text { Finalidad } \\
\text { de uso }\end{array}$ & Estrato & $\begin{array}{l}\text { Abundancia } \\
\text { relativa }\end{array}$ & Hábitat \\
\hline \multicolumn{8}{|l|}{ Chrysobalanaceae } \\
\hline Hirtella americana L. & A. Durán F. 161 & Moste, Moche & $\mathrm{Ar}$ & ARTE & III & $\mathrm{E}$ & SAP \\
\hline Hirtella triandra Sw. & $\begin{array}{l}\text { A. Durán F. 272, } \\
330\end{array}$ & Moste & $\mathrm{Ar}$ & ARTE & IV & $\mathrm{E}$ & SAP \\
\hline \multicolumn{8}{|l|}{ Clethraceae } \\
\hline Clethra suaveolens Turcz. & $\begin{array}{l}\text { A. Durán F. 026, } \\
091\end{array}$ & $\begin{array}{l}\text { Yox kun che } \\
\text { apto kap, Kukun } \\
\text { che ak tum kap }\end{array}$ & $\operatorname{Ar}$ & $\begin{array}{l}\text { LEÑA, MACO, } \\
\text { CEMI }\end{array}$ & & $\mathrm{ME}$ & SAP \\
\hline \multicolumn{8}{|l|}{ Clusiaceae } \\
\hline Calophyllum brasiliense Cambess. & $\begin{array}{l}\text { A. Durán F. 023, } \\
424\end{array}$ & $\begin{array}{l}\text { Baba, Bari, } \\
\text { Kisik che }\end{array}$ & $\mathrm{Ar}$ & INTR, MACO & V & PA & SAP \\
\hline Clusia flava Jacq. & A. Durán F. 1079 & A chulup & Har & & IV & & SAP \\
\hline Clusia guatemalensis Hemsl. & A. Durán F. 118 & & Har & & IV & $\mathrm{E}$ & SAP \\
\hline Clusia lundellii Standl. & A. Durán F. 034 & Tzoy & $\mathrm{Li}$ & & IV & $\mathrm{E}$ & SAP \\
\hline Clusia rosea Jacq. & A. Durán F. 183 & Kajan che & Har & AROM & IV & $\mathrm{E}$ & SAP \\
\hline Clusia salvinii Donn.Sm. & $\begin{array}{l}\text { A. Durán F. 065, } \\
151\end{array}$ & $\begin{array}{l}\text { Kopo, Una } \\
\text { Tzoy }\end{array}$ & Har & COLO, MEDI & IV & ME & SAP \\
\hline Garcinia intermedia (Pittier) Hammel & $\begin{array}{l}\text { A. Durán F. 264, } \\
503\end{array}$ & Sut k'ut che & $\mathrm{Ar}$ & ALIM & III & A & SAP \\
\hline \multicolumn{8}{|l|}{ Combretaceae } \\
\hline $\begin{array}{l}\text { Terminalia amazonia (J.F.Gmel.) } \\
\text { Exell }\end{array}$ & $\begin{array}{l}\text { A. Durán F. 005, } \\
105\end{array}$ & Pucte, Canhan & Ar & MACO, LEÑA & VI & MA & SAP \\
\hline \multicolumn{8}{|l|}{ Convolvulaceae } \\
\hline Ipomoea batatoides Choisy & A. Durán F. 732 & & $\mathrm{Li}$ & & & & AVS \\
\hline $\begin{array}{l}\text { Merremia discoidesperma (Donn. } \\
\text { Sm.) O'Donell }\end{array}$ & A. Durán F. 1211 & Mejen poxak & Te & & V & & SAP \\
\hline \multicolumn{8}{|l|}{ Cucurbitaceae } \\
\hline $\begin{array}{l}\text { Citrullus lanatus (Thunb.) Matsum. } \\
\text { \& Nakai }\end{array}$ & A. Durán F. 616 & Sanya, Sandia & $\mathrm{Te}$ & ALIM & & & $\mathrm{PCM}$ \\
\hline Cucurbita argyrosperma C.Huber & A. Durán F. 698 & & Te & MEDI & & & AVS \\
\hline Gurania makoyana (Lem.) Cogn. & A. Durán F. 121 & Yoch a chacara & Te & & II & ME & SAP \\
\hline Lagenaria siceraria (Molina) Standl. & A. Durán F. 585 & Lek & Te & UTDO & & & PCM \\
\hline Melothria pendula L. & A. Durán F. 599 & $\begin{array}{l}\text { Sanya de } \\
\text { murcielago }\end{array}$ & Te & & & & AVS \\
\hline Momordica charantia L. & A. Durán F. 744 & & Te & ALIM & & & PCM \\
\hline $\begin{array}{l}\text { Sechium edule (Jacq.) Sw. } \\
\text { Dilleniaceae }\end{array}$ & A. Durán F. 623 & Kum & $\mathrm{He}$ & ALIM & & & PCM \\
\hline $\begin{array}{l}\text { Doliocarpus dentatus (Aubl.) Standl. } \\
\text { Dipentodontaceae }\end{array}$ & A. Durán F. 319 & A sa ha & $\mathrm{Li}$ & ALFA & V & ME & SAP \\
\hline Perrottetia longistylis Rose & A. Durán F. 702 & Yitzin chak che & $\mathrm{Ar}$ & ALFA & & & SAP \\
\hline \multicolumn{8}{|l|}{ Euphorbiaceae } \\
\hline Acalypha diversifolia Jacq. & $\begin{array}{l}\text { A. Durán F. 516, } \\
611\end{array}$ & $\begin{array}{l}\text { Alolo che, } \\
\text { Chirituch wits }\end{array}$ & $\mathrm{Ar}$ & ALFA & & & SAP \\
\hline Acalypha macrostachya Jacq. & $\begin{array}{l}\text { A. Durán F. 132, } \\
448\end{array}$ & $\begin{array}{l}\text { Xa yan che, } \\
\text { Takain che }\end{array}$ & $\mathrm{He}$ & & II & $\mathrm{E}$ & SAP \\
\hline Acalypha skutchii I.M.Johnst. & A. Durán F. 304 & $\begin{array}{l}\text { Chirituch che, } \\
\text { Chiturich }\end{array}$ & $\mathrm{Ab}$ & & II & $\mathrm{E}$ & SAP \\
\hline Alchornea latifolia Sw. & $\begin{array}{l}\text { A. Durán F. 116, } \\
339,391\end{array}$ & $\begin{array}{l}\text { Kusu che/ Musan } \\
\text { che, Ukun che }\end{array}$ & & MACO, LEÑA & V & A & SAP \\
\hline
\end{tabular}


Apéndice 1. Continuación

\begin{tabular}{|c|c|c|c|c|c|c|c|}
\hline Clado/Familia/Especie & Recolecta & Nombre común & $\begin{array}{l}\text { Forma } \\
\text { vital }\end{array}$ & $\begin{array}{l}\text { Finalidad } \\
\text { de uso }\end{array}$ & Estrato & $\begin{array}{l}\text { Abundancia } \\
\text { relativa }\end{array}$ & Hábitat \\
\hline $\begin{array}{l}\text { Croton billbergianus subsp. } \\
\text { pyramidalis (Donn.Sm.) G.L.Webster }\end{array}$ & A. Durán F. 40 & Sac pajen che & $\mathrm{Ar}$ & MACO, ALIM & III & $\mathrm{E}$ & SAP \\
\hline Croton guatemalensis Lotsy & A. Durán F. 115 & Sac pan che & $\mathrm{Ar}$ & LEÑA & II & $\mathrm{E}$ & SAP \\
\hline Croton xalapensis Kunth & A. Durán F. 422 & Chak tabi wits & $\mathrm{Ar}$ & & III & $\mathrm{E}$ & SAP \\
\hline Euphorbia hyssopifolia L. & A. Durán F. 667 & Sak ich & $\mathrm{He}$ & MEDI & & & AVS \\
\hline Garcia nutans Vahl ex Rohr & A. Durán F. 030 & Kusunche & $\mathrm{Ar}$ & MEDI & IV & ME & SAP \\
\hline Mabea excelsa Standl. \& Steyerm. & $\begin{array}{l}\text { A. Durán F. 255, } \\
303\end{array}$ & Utzon che & $\operatorname{Ar}$ & ALFA & V & $\mathrm{E}$ & SAP \\
\hline $\begin{array}{l}\text { Manihot esculenta Crantz } \\
\text { Fabaceae }\end{array}$ & A. Durán F. 596 & Tzin/ Yuca & $\mathrm{He}$ & ALIM & & & PCM \\
\hline $\begin{array}{l}\text { Abarema zolleriana (Standl. \& } \\
\text { Steyerm.) Barneby \& J.W. Grimes }\end{array}$ & A. Durán F. 426 & & $\mathrm{Ar}$ & & III & $\mathrm{E}$ & SAP \\
\hline Bauhinia pansamalana Donn.Sm. & A. Durán F. 260 & Che & $\mathrm{Ar}$ & & II & ME & SAP \\
\hline Bauhinia rubeleruziana Donn.Sm. & A. Durán F. 174 & Kan che & $\mathrm{Ar}$ & $\begin{array}{l}\text { MACO, } \\
\text { UTDO }\end{array}$ & IV & $\mathrm{E}$ & SAP \\
\hline $\begin{array}{l}\text { Calliandra tergemina var. emarginata } \\
\text { (Willd.) Barneby }\end{array}$ & A. Durán F. 373 & Kuiyan che & $\operatorname{Ar}$ & & III & $\mathrm{E}$ & SAP \\
\hline Chamaecrista nictitans (L.) Moench & A. Durán F. 633 & & $\mathrm{He}$ & & I & A & AVS \\
\hline Cojoba arborea (L.) Britton \& Rose & $\begin{array}{l}\text { A. Durán F. 094, } \\
134\end{array}$ & Buche & $\operatorname{Ar}$ & $\begin{array}{l}\text { MACO, LEÑA, } \\
\text { ALFA }\end{array}$ & & ME & SAP \\
\hline Crotalaria incana L. & A. Durán F. 692 & Chikirin lobi & $\mathrm{He}$ & & & & AVS \\
\hline Crotalaria longirostrata Hook. \& Arn. & A. Durán F. 551 & Chipilin & $\mathrm{He}$ & ALIM & & & SAP \\
\hline Dalbergia glomerata Hemsl. & A. Durán F. 605 & Tzam che & $\mathrm{Ar}$ & LEÑA & & & AVS \\
\hline Desmodium aparines (Link) DC. & A. Durán F. 543 & $\begin{array}{l}\text { Tzaya zay } \\
\text { nukuch }\end{array}$ & $\mathrm{He}$ & & & & AVS \\
\hline Desmodium incanum DC. & A. Durán F. 541 & $\begin{array}{l}\text { Mejen a } \\
\text { tzayan za }\end{array}$ & $\mathrm{He}$ & & & & AVS \\
\hline $\begin{array}{l}\text { Desmodium macrodesmum } \\
\text { (S.F.Blake) Standl. \& Steyerm. }\end{array}$ & $\begin{array}{l}\text { A. Durán F. 143, } \\
335\end{array}$ & $\begin{array}{l}\text { Tzap pu xibi, } \\
\text { Tza tza le ak }\end{array}$ & $\mathrm{Te}$ & & III & ME & SAP \\
\hline $\begin{array}{l}\text { Desmodium metallicum (Rose \& } \\
\text { Standl.) Standl. }\end{array}$ & A. Durán F. 241 & Che & $\mathrm{Li}$ & & III & ME & SAP \\
\hline Dialium guianense (Aubl.) Sandwith & A. Durán F. 154 & $\begin{array}{l}\text { Wuech, } \\
\text { Guapake }\end{array}$ & Ar & ALIM & $\mathrm{VI}$ & MA & SAP \\
\hline Dussia mexicana (Standl.) Harms & A. Durán F. 395 & A soo ja an che & $\mathrm{Ar}$ & & VI & A & SAP \\
\hline Erythrina berteroana Urb. & A. Durán F. 352 & Kante & $\mathrm{Ar}$ & $\begin{array}{l}\text { COLO, ARTE, } \\
\text { CEVI }\end{array}$ & III & $\mathrm{E}$ & SAP \\
\hline Inga belizensis Standl. & A. Durán F. 219 & Bits wits & $\mathrm{Ar}$ & ALIM & III & ME & SAP \\
\hline Inga pavoniana G.Don & A. Durán F. 302 & Tzeren bits & $\mathrm{Ar}$ & ALIM & V & ME & SAP \\
\hline Inga punctata Willd. & A. Durán F. 394 & Mejen tete bits & $\mathrm{Ar}$ & & IV & ME & SAP \\
\hline Inga sp. & A. Durán F. 380 & Sa kum che & $\mathrm{Ar}$ & ARTE & IV & $\mathrm{E}$ & SAP \\
\hline $\begin{array}{l}\text { Leucaena diversifolia (Schltdl.) } \\
\text { Benth. }\end{array}$ & $\begin{array}{l}\text { A. Durán F. 418, } \\
657\end{array}$ & Uatan che & $\mathrm{Ar}$ & & III & $\mathrm{E}$ & SAP \\
\hline $\begin{array}{l}\text { Leucaena pulverulenta (Schltdl.) } \\
\text { Benth. }\end{array}$ & A. Durán F. 067 & Saran & $\mathrm{Ar}$ & LEÑA, INTR & III & PA & SAP \\
\hline Lonchocarpus rugosus Benth. & A. Durán F. 425 & Machich che & $\mathrm{Ar}$ & MACO & IV & $\mathrm{E}$ & SAP \\
\hline Lonchocarpus verrucosus M.Sousa & A. Durán F. 410 & $\begin{array}{l}\text { Jobillo, Yax } \\
\text { pa che }\end{array}$ & $\mathrm{Ar}$ & ARTE & III & $\mathrm{E}$ & SAP \\
\hline Mimosa pudica L. & A. Durán F. 1320 & & $\mathrm{He}$ & & I & A & SAP \\
\hline Ormosia schippii Standl. \& Steyerm. & A. Durán F. s/n & Am & $\mathrm{Ar}$ & ARTE & & & SAP \\
\hline
\end{tabular}


Apéndice 1. Continuación

\begin{tabular}{|c|c|c|c|c|c|c|c|}
\hline Clado/Familia/Especie & Recolecta & Nombre común & $\begin{array}{l}\text { Forma } \\
\text { vital }\end{array}$ & $\begin{array}{l}\text { Finalidad } \\
\text { de uso }\end{array}$ & Estrato & $\begin{array}{l}\text { Abundancia } \\
\text { relativa }\end{array}$ & Hábitat \\
\hline Phaseolus lunatus L. & A. Durán F. 730 & A bur, Ib & $\mathrm{He}$ & ALIM & & & PCM \\
\hline Phaseolus vulgaris $\mathrm{L}$. & $\begin{array}{l}\text { A. Durán F. 688, } \\
689,729\end{array}$ & $\begin{array}{l}\text { Chei bur, } \\
\text { Ek bur }\end{array}$ & $\mathrm{He}$ & ALIM & & & PCM \\
\hline Psoralea rhombifolia Torr. \& A.Gray & A. Durán F. 638 & & $\mathrm{He}$ & & & & AVS \\
\hline $\begin{array}{l}\text { Rhynchosia erythrinoides Schltdl. } \\
\quad \text { \& Cham. }\end{array}$ & A. Durán F. 003 & Chochi ak & $\mathrm{Li}$ & & IV & ME & SAP \\
\hline Rhynchosia nelsonii (Rose) Grear & A. Durán F. 1277 & Chac mo ak & Te & ARTE & V & & SAP \\
\hline Rhynchosia pyramidalis (Lam.) Urb. & $\begin{array}{l}\text { A. Durán F. 334, } \\
524\end{array}$ & Mo ak & $\mathrm{Li}$ & ARTE & V & ME & SAP \\
\hline $\begin{array}{l}\text { Senna fruticosa (Mill.) H.S.Irwin } \\
\quad \& \text { Barneby }\end{array}$ & A. Durán F. 746 & & $\mathrm{Ar}$ & & & & AVS \\
\hline $\begin{array}{l}\text { Senna racemosa (Mill.) H.S.Irwin } \\
\quad \& \text { Barneby }\end{array}$ & A. Durán F. 359 & Jai patan ak & $\mathrm{Li}$ & MEDI & IV & PA & SAP \\
\hline $\begin{array}{l}\text { Vigna peduncularis (Kunth) Fawc. } \\
\text { \& Rendle }\end{array}$ & A. Durán F. 534 & & $\mathrm{He}$ & & & & SAP \\
\hline $\begin{array}{l}\text { Vigna umbellata (Thunb.) Ohwi \& } \\
\text { H.Ohashi }\end{array}$ & A. Durán F. 728 & Arroz bur & $\mathrm{He}$ & ALIM & & & AVS \\
\hline Vigna unguiculata (L.) Walp. & $\begin{array}{l}\text { A. Durán F. 718, } \\
727\end{array}$ & A bur, A bur box & $\mathrm{He}$ & ALIM & & & PCM \\
\hline $\begin{array}{l}\text { Zapoteca ravenii H.M.Hern. } \\
\text { Fagaceae }\end{array}$ & A. Durán F. 641 & & $\mathrm{Ab}$ & & & & SAP \\
\hline Quercus lancifolia Schltdl. \& Cham. & A. Durán F. 409 & Ixim charo & $\mathrm{Ar}$ & MACO, JUGE & V & PA & SAP \\
\hline Quercus skinneri Benth. & A. Durán F. 102 & $\begin{array}{l}\text { Charo, Karote, } \\
\text { Avellano }\end{array}$ & $\mathrm{Ar}$ & MACO, JUGE & $\mathrm{VI}$ & PA & SAP \\
\hline \multicolumn{8}{|l|}{ Gentianaceae } \\
\hline $\begin{array}{l}\text { Lisianthius brevidentatus (Hemsl.) } \\
\text { Kuntze }\end{array}$ & A. Durán F. 583 & & $\mathrm{He}$ & & & & AVS \\
\hline $\begin{array}{l}\text { Voyria parasitica (Schltdl. \& Cham.) } \\
\text { Ruyters \& Maas }\end{array}$ & A. Durán F. 673 & Bklu ruch & Sa & & & & SAP \\
\hline \multicolumn{8}{|l|}{ Gesneriaceae } \\
\hline Columnea purpusii Standl. & A. Durán F. 316 & & Hab & & II & $\mathrm{E}$ & SAP \\
\hline Drymonia strigosa (Oerst.) Wiehler & $\begin{array}{l}\text { A. Durán F. 117, } \\
317\end{array}$ & Kuran che & Hab & & II & ME & SAP \\
\hline $\begin{array}{l}\text { Solenophora wilsonii Standl. } \\
\text { Icacinaceae }\end{array}$ & A. Durán F. 708 & & $\mathrm{He}$ & & & & SAP \\
\hline $\begin{array}{l}\text { Oecopetalum mexicanum Greenm. } \\
\text { \& C.H. Thomps. }\end{array}$ & A. Durán F. 152 & $\begin{array}{l}\text { Kakate, } \\
\text { Kukun che }\end{array}$ & Ar & ALIM & IV & $\mathrm{E}$ & SAP \\
\hline \multicolumn{8}{|l|}{ Loganiaceae } \\
\hline Spigelia scabra Cham. \& Schltdl. & A. Durán F. 327 & & $\mathrm{He}$ & MEDI & I & ME & SAP \\
\hline Strychnos brachistantha Standl. & A. Durán F. 381 & O pak & $\mathrm{Li}$ & & IV & ME & SAP \\
\hline $\begin{array}{l}\text { Strychnos panamensis Seem. } \\
\text { Loranthaceae }\end{array}$ & A. Durán F. 312 & Uzan kan & $\mathrm{Li}$ & MEDI & II & $\mathrm{E}$ & SAP \\
\hline $\begin{array}{l}\text { Struthanthus cassythoides Millsp. } \\
\text { ex Standl. }\end{array}$ & $\begin{array}{l}\text { A. Durán F. 1182, } \\
1230\end{array}$ & & Par & & & & SAP \\
\hline $\begin{array}{l}\text { Struthanthus hartwegii (Benth.) } \\
\text { Standl. }\end{array}$ & $\begin{array}{l}\text { A. Durán F. 1231, } \\
1248\end{array}$ & & Par & & & & SAP \\
\hline \multicolumn{8}{|l|}{ Lythraceae } \\
\hline Cuphea appendiculata Benth. & $\begin{array}{l}\text { A. Durán F. } \\
\text { s/n, } 650\end{array}$ & & $\mathrm{Ab}$ & & & & SAP \\
\hline
\end{tabular}


Apéndice 1. Continuación

\begin{tabular}{|c|c|c|c|c|c|c|c|}
\hline Clado/Familia/Especie & Recolecta & Nombre común & $\begin{array}{l}\text { Forma } \\
\text { vital }\end{array}$ & $\begin{array}{l}\text { Finalidad } \\
\text { de uso }\end{array}$ & Estrato & $\begin{array}{l}\text { Abundancia } \\
\text { relativa }\end{array}$ & Hábitat \\
\hline \multicolumn{8}{|l|}{ Malpighiaceae } \\
\hline Bunchosia lindeniana A.Juss. & A. Durán F. 1236 & Sipche & $\mathrm{Ar}$ & ALIM & IV & A & SAP \\
\hline Heteropterys aff. cotinifolia A. Juss. & A. Durán F. 333 & U yo yo ak & $\mathrm{Li}$ & FUAG & V & ME & SAP \\
\hline Hiraea fagifolia (DC.) A.Juss. & A. Durán F. 612 & Nukurum ak & $\mathrm{Li}$ & LEÑA & & & SAP \\
\hline $\begin{array}{l}\text { Mascagnia aff. dipholiphylla } \\
\text { (Small) Bullock }\end{array}$ & A. Durán F. 321 & Xo chocho ak & $\mathrm{Li}$ & LEÑA & V & ME & SAP \\
\hline $\begin{array}{l}\text { Stigmaphyllon dichotomum (L.) } \\
\text { Griseb. }\end{array}$ & A. Durán F. 1367 & Tzakaki & $\mathrm{Te}$ & & III & & SAP \\
\hline $\begin{array}{l}\text { Tetrapterys schiedeana Schltdl. } \\
\text { \& Cham. }\end{array}$ & A. Durán F. 144 & Kat ak & $\mathrm{Li}$ & & II & ME & SAP \\
\hline \multicolumn{8}{|l|}{ Malvaceae } \\
\hline Bernoullia flammea Oliv. & A. Durán F. 336 & Pon che & $\mathrm{Ar}$ & $\begin{array}{l}\text { CERE, ALIM, } \\
\text { MACO }\end{array}$ & VI & $\mathrm{E}$ & SAP \\
\hline Guazuma ulmifolia Lam. & A. Durán F. 601 & $\begin{array}{l}\text { Utzak kik } \\
\text { upnaki }\end{array}$ & $\mathrm{Ar}$ & MEDI & & & SAP \\
\hline Hampea stipitata S.Watson & A. Durán F. 250 & Che & $\mathrm{Ar}$ & FIBR & III & $\mathrm{E}$ & SAP \\
\hline Heliocarpus appendiculatus Turcz. & $\begin{array}{l}\text { A. Durán F. 270, } \\
449\end{array}$ & Jaror & $\mathrm{Ar}$ & FIBR, MACO & IV & $\mathrm{E}$ & SAP \\
\hline Heliocarpus donnellsmithii Rose & $\begin{array}{l}\text { A. Durán F. 251, } \\
1099\end{array}$ & $\begin{array}{l}\text { Halo che, } \\
\text { majahua }\end{array}$ & $\mathrm{Ar}$ & FIBR & IV & A & SAP \\
\hline Malvaviscus arboreus Cav. & A. Durán F. 699 & A tamí & $\mathrm{Ar}$ & MEDI & & & SAP \\
\hline Mortoniodendron vestitum Lundell & A. Durán F. 402 & Sac pakte che & $\mathrm{Ar}$ & & III & $\mathrm{E}$ & SAP \\
\hline $\begin{array}{l}\text { Pseudobombax ellipticum } \\
\text { (Kunth) Dugand }\end{array}$ & A. Durán F. 106 & Chute & $\mathrm{Ar}$ & $\begin{array}{l}\text { LEÑA, FIBR, } \\
\text { UTDO }\end{array}$ & V & $\mathrm{E}$ & SAP \\
\hline $\begin{array}{l}\text { Quararibea funebris (La Llave) } \\
\text { Vischer }\end{array}$ & A. Durán F. 1156 & Majas & $\mathrm{Ar}$ & INTR & III & & SAP \\
\hline $\begin{array}{l}\text { Trichospermum mexicanum } \\
\text { (DC.) Baill. }\end{array}$ & $\begin{array}{l}\text { A. Durán F. 248, } \\
411\end{array}$ & $\begin{array}{l}\text { Mahaua, } \\
\text { Tab che }\end{array}$ & $\operatorname{Ar}$ & $\begin{array}{l}\text { FIBR, LEÑA, } \\
\text { UTDO }\end{array}$ & V & ME & SAP \\
\hline \multicolumn{8}{|l|}{ Marcgraviaceae } \\
\hline Marcgravia mexicana Gilg & A. Durán F. 377 & Al tza kan ak & $\mathrm{Li}$ & & IV & ME & SAP \\
\hline \multicolumn{8}{|l|}{ Melastomataceae } \\
\hline $\begin{array}{l}\text { Arthrostemma ciliatum Pav. } \\
\text { ex D. Don }\end{array}$ & A. Durán F. s/n & & Te & & & & SAP \\
\hline Arthrostemma parvifolium Cogn. & A. Durán F. 549 & & $\mathrm{He}$ & & & & AVS \\
\hline $\begin{array}{l}\text { Clidemia aff. petiolaris (Schltdl. \& } \\
\text { Cham.) Schltdl. ex Triana }\end{array}$ & A. Durán F. 135 & Pakam che & $\mathrm{He}$ & MEDI, ALIM & II & PA & SAP \\
\hline $\begin{array}{l}\text { Clidemia laxiflora (Schltdl.) Walp. } \\
\text { ex Naudin }\end{array}$ & A. Durán F. 049 & Hoitei che & $\mathrm{Ab}$ & ALIM & II & $\mathrm{ME}$ & SAP \\
\hline Clidemia setosa (Triana) Gleason & $\begin{array}{l}\text { A. Durán F. 052, } \\
199\end{array}$ & Pakam re xib & $\mathrm{He}$ & & 1 & PA & SAP \\
\hline Conostegia caelestis Standl. & A. Durán F. 148 & Bayan che & $\mathrm{Ar}$ & & III & A & SAP \\
\hline $\begin{array}{l}\text { Conostegia icosandra (Sw. ex } \\
\text { Wikstr.) Urb. }\end{array}$ & A. Durán F. 185 & Yoch a cher & $\mathrm{Ar}$ & ALFA & III & $\mathrm{E}$ & SAP \\
\hline $\begin{array}{l}\text { Conostegia superba D. Don } \\
\text { ex Naudin }\end{array}$ & A. Durán F. 713 & Yos joroch pum & $\mathrm{Ar}$ & ALFA & & & SAP \\
\hline Miconia affinis DC. & A. Durán F. 1153 & Yax jote che & $\mathrm{Ar}$ & & III & & SAP \\
\hline Miconia barbinervis (Benth.) Triana & A. Durán F. 308 & Ukusa che & $\mathrm{Ar}$ & & IV & PA & SAP \\
\hline Miconia desmantha Benth. & A. Durán F. 1154 & Mejen jote che & $\mathrm{Ar}$ & ALIM & III & & SAP \\
\hline
\end{tabular}


Apéndice 1. Continuación

\begin{tabular}{|c|c|c|c|c|c|c|c|}
\hline Clado/Familia/Especie & Recolecta & Nombre común & $\begin{array}{l}\text { Forma } \\
\text { vital }\end{array}$ & $\begin{array}{l}\text { Finalidad } \\
\text { de uso }\end{array}$ & Estrato & $\begin{array}{l}\text { Abundancia } \\
\text { relativa }\end{array}$ & Hábitat \\
\hline Miconia dodecandra Cogn. & $\begin{array}{l}\text { A. Durán F. 056, } \\
\text { 122, } 186\end{array}$ & $\begin{array}{l}\text { Sac pajen che, } \\
\text { Uyo cha cher, } \\
\text { Yox ox a koch }\end{array}$ & $\operatorname{Ar}$ & ARTE & II & $\mathrm{E}$ & SAP \\
\hline Miconia fulvostellata L.O. Williams & A. Durán F. 406 & Yooch che koch & $\mathrm{Ar}$ & & II & ME & SAP \\
\hline Miconia hyperprasina Naudin & A. Durán F. 123 & Yo ox koch & $\mathrm{Ab}$ & & III & A & SAP \\
\hline $\begin{array}{l}\text { Miconia impetiolaris (Sw.) D. } \\
\text { Don ex DC. }\end{array}$ & A. Durán F. 173 & Sa sai che & $\mathrm{Ab}$ & & II & $\mathrm{E}$ & SAP \\
\hline Miconia sylvatica (Schltdl.) Naudin & A. Durán F. 458 & Wowo che & $\mathrm{Ar}$ & & & & SAP \\
\hline Topobea laevigata (D. Don) Naudin & $\begin{array}{l}\text { A. Durán F. 066, } \\
344,650\end{array}$ & $\begin{array}{l}\text { Churan, Yitzin } \\
\text { kajanche }\end{array}$ & Har, Te & COLO & V & $\mathrm{E}$ & $\begin{array}{l}\text { AVS, } \\
\text { SAP }\end{array}$ \\
\hline \multicolumn{8}{|l|}{ Meliaceae } \\
\hline Cedrela odorata L. & $\begin{array}{l}\text { A. Durán F. 397, } \\
421\end{array}$ & $\begin{array}{l}\text { Mejen kan or, } \\
\text { Cedro, Kun che }\end{array}$ & $\mathrm{Ar}$ & $\begin{array}{l}\text { MACO, ARTE, } \\
\text { INTR, UTDO, } \\
\text { CEMI }\end{array}$ & V & $\mathrm{E}$ & SAP \\
\hline Guarea glabra Vahl & $\begin{array}{l}\text { A. Durán F. 016, } \\
214,222,029 \\
170\end{array}$ & $\begin{array}{l}\text { Puna, Caoba, } \\
\text { Nukuch sawua } \\
\text { che, Saguache, } \\
\text { Nukuch sacba ch }\end{array}$ & Ar & $\begin{array}{l}\text { MACO, } \\
\text { UTDO, CERE }\end{array}$ & V & PA & SAP \\
\hline Swietenia macrophylla King & A. Durán F. 392 & Yax jub che & $\mathrm{Ar}$ & $\begin{array}{l}\text { INTR, MACO, } \\
\text { UTDO }\end{array}$ & VI & PA & SAP \\
\hline Trichilia japurensis C. DC. & A. Durán F. 22 & Aranchan & $\mathrm{Ar}$ & ALIM & III & $\mathrm{E}$ & SAP \\
\hline $\begin{array}{l}\text { Trichilia quadrijuga subsp. } \\
\text { cinerascens (C. DC.) T.D. Penn. } \\
\text { Menispermaceae }\end{array}$ & $\begin{array}{l}\text { A. Durán F. 149, } \\
400\end{array}$ & Ara xa che & $\mathrm{Ar}$ & ALIM & IV & $\mathrm{E}$ & SAP \\
\hline Cissampelos pareira L. & A. Durán F. 517 & Ahuatan che & Te & & & & SAP \\
\hline $\begin{array}{l}\text { Disciphania calocarpa Standl. } \\
\text { Moraceae }\end{array}$ & A. Durán F. 301 & Pa ak & $\mathrm{Li}$ & ALIM & V & ME & SAP \\
\hline Ficus apollinaris Dugand & $\begin{array}{l}\text { A. Durán F. 156, } \\
218,311\end{array}$ & $\begin{array}{l}\text { Chimo, Jun, } \\
\text { Ak jun che }\end{array}$ & Har & VEST, ALFA & VI & $\mathrm{PA}$ & SAP \\
\hline Ficus pertusa L.f. & A. Durán F. 325 & Mejen kopo & Har & & VI & $\mathrm{E}$ & SAP \\
\hline $\begin{array}{l}\text { Pseudolmedia glabrata (Liebm.) } \\
\text { C.C.Berg }\end{array}$ & $\begin{array}{l}\text { A. Durán F. 019, } \\
020,145,150\end{array}$ & $\begin{array}{l}\text { Bamax, Tzot } \\
\text { Bamax, Has } \\
\text { bamax }\end{array}$ & Ar & ALIM, INTR & V & MA & SAP \\
\hline Trophis mexicana (Liebm.) Bureau & $\begin{array}{l}\text { A. Durán F. 107, } \\
343,594\end{array}$ & $\begin{array}{l}\text { Uchey pa, Sipna } \\
\text { che, Cheipa }\end{array}$ & $\mathrm{Ar}$ & ALIM & IV & A & SAP \\
\hline Trophis racemosa (L.) Urb. & $\begin{array}{l}\text { A. Durán F. 507, } \\
542\end{array}$ & $\begin{array}{l}\text { Bayon che, } \\
\text { Sabak che }\end{array}$ & $\mathrm{Ar}$ & & & & SAP \\
\hline \multicolumn{8}{|l|}{ Muntingiaceae } \\
\hline $\begin{array}{l}\text { Muntingia calabura L. } \\
\text { Myrtaceae }\end{array}$ & \multicolumn{6}{|c|}{ Myrtaceae } & AVS \\
\hline Calyptranthes schiedeana O.Berg & A. Durán F. 609 & Peris che & $\mathrm{Ar}$ & ALIM & & & AVS \\
\hline Eugenia acapulcensis Steud. & A. Durán F. 372 & A xib & $\mathrm{Ab}$ & ALIM & III & $\mathrm{E}$ & SAP \\
\hline $\begin{array}{l}\text { Eugenia capuli (Schltdl. \& Cham.) } \\
\text { Hook. \& Arn. }\end{array}$ & A. Durán F. 598 & Axinch che & $\mathrm{Ar}$ & ALIM & & & SAP \\
\hline Eugenia tikalana Lundell & A. Durán F. 090 & Xin che & $\mathrm{Ab}$ & ALIM & II & $\mathrm{E}$ & SAP \\
\hline Myrcia splendens (Sw.) DC. & A. Durán F. 064 & Mujun che & $\mathrm{Ar}$ & & III & $\mathrm{E}$ & SAP \\
\hline Pimenta dioica (L.) Merr. & $\begin{array}{l}\text { A. Durán F. 305, } \\
223\end{array}$ & $\begin{array}{l}\text { Pesa che, } \\
\text { Pimienta }\end{array}$ & $\mathrm{Ar}$ & ALIM, MEDI & IV & ME & SAP \\
\hline Psidium guajava L. & A. Durán F. 533 & Pichik, Guayaba & $\mathrm{Ar}$ & ALMI, MEDI & & & PCM \\
\hline
\end{tabular}


Apéndice 1. Continuación

\begin{tabular}{|c|c|c|c|c|c|c|c|}
\hline Clado/Familia/Especie & Recolecta & Nombre común & $\begin{array}{l}\text { Forma } \\
\text { vital }\end{array}$ & $\begin{array}{l}\text { Finalidad } \\
\text { de uso }\end{array}$ & Estrato & $\begin{array}{l}\text { Abundancia } \\
\text { relativa }\end{array}$ & Hábitat \\
\hline $\begin{array}{l}\text { Psidium guineense Sw. } \\
\text { Nyctaginaceae }\end{array}$ & A. Durán F. 629 & & $\operatorname{Ar}$ & ALMI, MEDI & & & AVS \\
\hline Mirabilis jalapa L. & $\begin{array}{l}\text { A. Durán F. 731, } \\
736\end{array}$ & & $\mathrm{He}$ & & & & AVS \\
\hline \multicolumn{8}{|l|}{ Oleaceae } \\
\hline Chionanthus ligustrinus (Sw.) Pers. & $\begin{array}{l}\text { A. Durán F. 179, } \\
310\end{array}$ & $\begin{array}{l}\text { Kaba che, } \\
\text { Tzo tzo che }\end{array}$ & $\mathrm{Ar}$ & MACO & V & $\mathrm{E}$ & SAP \\
\hline $\begin{array}{l}\text { Fraxinus uhdei (Wenz.) Lingelsh. } \\
\text { Onagraceae }\end{array}$ & A. Durán F. 164 & Sac churu che & $\mathrm{Ar}$ & & V & $\mathrm{E}$ & SAP \\
\hline $\begin{array}{l}\text { Hauya elegans subsp. cornuta } \\
\text { (Hemsl.) P.H.Raven \& Breedlove }\end{array}$ & $\begin{array}{l}\text { A. Durán F. 068, } \\
162,417,1234\end{array}$ & $\begin{array}{l}\text { Karan che, } \\
\text { Ku ura che, } \\
\text { Yoch ax Kuzan }\end{array}$ & $\mathrm{Ar}$ & MACO, LEÑA & III & $\mathrm{E}$ & SAP \\
\hline $\begin{array}{l}\text { Ludwigia octovalvis (Jacq.) P.H.Raven } \\
\text { Passifloraceae }\end{array}$ & A. Durán F. 518 & K'u si che & $\mathrm{He}$ & & & & AVS \\
\hline Passiflora aff. ambigua Hemsl. & A. Durán F. 267 & & Te & & I & ME & SAP \\
\hline Passiflora cobanensis Killip & A. Durán F. 142 & Kumi cho & Te & & III & ME & SAP \\
\hline Passiflora cookii Killip & $\begin{array}{l}\text { A. Durán F. 269, } \\
318\end{array}$ & $\begin{array}{l}\text { Chi kan ki, } \\
\text { Chin ka kir }\end{array}$ & $\mathrm{Te}$ & ALIM & V & ME & SAP \\
\hline \multicolumn{8}{|l|}{ Pentaphylacaceae } \\
\hline $\begin{array}{l}\text { Symplococarpon purpusii } \\
\text { (Brandegee) Kobuski }\end{array}$ & A. Durán F. 662 & & $\mathrm{Ar}$ & LEÑA & & & SAP \\
\hline $\begin{array}{l}\text { Ternstroemia tepezapote Cham. } \\
\text { \& Schltdl. }\end{array}$ & A. Durán F. 181 & Chak pach & $\mathrm{Ar}$ & LEÑA, MEDI & III & $\mathrm{E}$ & SAP \\
\hline \multicolumn{8}{|l|}{ Petenaeaceae } \\
\hline $\begin{array}{l}\text { Petenaea cordata Lundell } \\
\text { Phyllanthaceae }\end{array}$ & \multicolumn{6}{|c|}{ Phyllanthaceae } & SAP \\
\hline $\begin{array}{l}\text { Margaritaria nobilis L.f. } \\
\text { Phytolaccaceae }\end{array}$ & \multicolumn{6}{|c|}{ Phytolaccaceae } & SAP \\
\hline $\begin{array}{l}\text { Phytolacca rivinoides Kunth \& } \\
\text { C.D.Bouché }\end{array}$ & A. Durán F. 625 & & $\mathrm{He}$ & & & & SAP \\
\hline \multicolumn{8}{|l|}{ Plantaginaceae } \\
\hline \multicolumn{8}{|l|}{ Polygalaceae } \\
\hline Monnina sylvatica Schltdl. \& Cham. & A. Durán F. 446 & Yax posto che & $\mathrm{He}$ & & & & AVS \\
\hline Polygala berlandieri S.Watson & A. Durán F. 645 & & $\mathrm{He}$ & & & & AVS \\
\hline Polygala jamaicensis Chodat & $\begin{array}{l}\text { A. Durán F. 415, } \\
597\end{array}$ & Kua che & $\mathrm{Ar}$ & & III & PA & SAP \\
\hline Polygala paniculata L. & A. Durán F. 665 & & $\mathrm{He}$ & & & & AVS \\
\hline Securidaca diversifolia (L.) S.F.Blake & $\begin{array}{l}\text { A. Durán F. 300, } \\
358\end{array}$ & $\begin{array}{l}\text { Kach che ak, } \\
\text { A kan ak }\end{array}$ & $\mathrm{Li}$ & ORNA, MEDI & V & ME & SAP \\
\hline \multicolumn{8}{|l|}{ Polygonaceae } \\
\hline Coccoloba aff. hondurensis Lundell & $\begin{array}{l}\text { A. Durán F. 210, } \\
374,429\end{array}$ & $\begin{array}{l}\text { Mejen bochich, } \\
\text { Bochich }\end{array}$ & $\mathrm{Ar}$ & $\begin{array}{l}\text { MACO, LEÑA, } \\
\text { ALIM }\end{array}$ & & $\mathrm{E}$ & SAP \\
\hline Coccoloba barbadensis Jacq. & A. Durán F. 386 & Nukux bochich & $\mathrm{Ar}$ & ALIM, INTR & IV & $\mathrm{E}$ & SAP \\
\hline $\begin{array}{l}\text { Coccoloba cozumelensis Hemsl. } \\
\text { Primulaceae }\end{array}$ & A. Durán F. 374 & & $\mathrm{Ar}$ & & IV & ME & SAP \\
\hline Ardisia aff. karwinskyana Mez & A. Durán F. 025 & Xiri & $\mathrm{Ar}$ & & III & PA & SAP \\
\hline
\end{tabular}


Apéndice 1. Continuación

\begin{tabular}{|c|c|c|c|c|c|c|c|}
\hline Clado/Familia/Especie & Recolecta & Nombre común & $\begin{array}{l}\text { Forma } \\
\text { vital }\end{array}$ & $\begin{array}{l}\text { Finalidad } \\
\text { de uso }\end{array}$ & Estrato & $\begin{array}{l}\text { Abundancia } \\
\text { relativa }\end{array}$ & Hábitat \\
\hline Ardisia compressa Kunth & $\begin{array}{l}\text { A. Durán F. 137, } \\
\text { 133, 201, 075, } \\
1081\end{array}$ & $\begin{array}{l}\text { Kikin barun } \\
\text { che, Pupute }\end{array}$ & $\operatorname{Ar}$ & ALIM & II & A & SAP \\
\hline Ardisia nigrescens Oerst. & $\begin{array}{l}\text { A. Durán F. 112, } \\
368\end{array}$ & $\begin{array}{l}\text { Pupu che, Jaya } \\
\text { re xim che }\end{array}$ & $\mathrm{Ab}$ & ALIM & II & PA & SAP \\
\hline Ardisia paschalis Donn.Sm. & A. Durán F. 054 & Popo xibi & Ar & ALIM, INTR & III & PA & SAP \\
\hline Ardisia revoluta Kunth & A. Durán F. 450 & Kuku che & $\operatorname{Ar}$ & LEÑA & & & SAP \\
\hline $\begin{array}{l}\text { Deherainia smaragdina (Planch. ex } \\
\text { Linden) Decne. }\end{array}$ & $\begin{array}{l}\text { A. Durán F. 114, } \\
348\end{array}$ & Sipche, Siki kax & $\mathrm{Ar}$ & $\begin{array}{l}\text { MACO, LEÑA, } \\
\text { ALIM }\end{array}$ & & ME & SAP \\
\hline $\begin{array}{l}\text { Parathesis cubana (A.DC.) Molinet } \\
\text { \& M.Gómez }\end{array}$ & A. Durán F. 594 & & $\mathrm{Ar}$ & & & & PAL \\
\hline Parathesis donnell-smithii Mez & $\begin{array}{l}\text { A. Durán F. 256, } \\
1287\end{array}$ & Pipizo che, che & $\mathrm{Ar}$ & ALFA & II, III & PA & SAP \\
\hline \multicolumn{8}{|l|}{ Rhamnaceae } \\
\hline Gouania lupuloides (L.) Urb. & $\begin{array}{l}\text { A. Durán F. 360, } \\
442\end{array}$ & $\begin{array}{l}\text { Suki ak, } \\
\text { K'uk'i ak }^{\prime}\end{array}$ & $\mathrm{Li}$ & MEDI & V & ME & SAP \\
\hline \multicolumn{8}{|l|}{ Rosaceae } \\
\hline Eriobotrya japonica (Thunb.) Lindl. & A. Durán F. 639 & nispero & $\mathrm{Ab}$ & ALIM & & & AVS \\
\hline Photinia microcarpa Standl. & A. Durán F. 322 & $\begin{array}{l}\text { Papa che, } \\
\text { Kajan che }\end{array}$ & $\mathrm{Ar}$ & $\begin{array}{l}\text { MACO, ALIM, } \\
\text { LEÑA }\end{array}$ & IV & A & SAP \\
\hline \multicolumn{8}{|l|}{ Rubiaceae } \\
\hline $\begin{array}{l}\text { Arachnothryx buddleioides (Benth.) } \\
\text { Planch. }\end{array}$ & $\begin{array}{l}\text { A. Durán F. 630, } \\
640\end{array}$ & & $\operatorname{Ar}$ & LEÑA & & & SAP \\
\hline $\begin{array}{l}\text { Arachnothryx capitellata (Hemsl.) } \\
\text { Borhidi }\end{array}$ & A. Durán F. 002 & Chac top che & $\mathrm{Ab}$ & $\mathrm{CHIC}$ & III & $\mathrm{E}$ & SAP \\
\hline $\begin{array}{l}\text { Arachnothryx gonzaleoides } \\
\text { (Standl.) Borhidi }\end{array}$ & A. Durán F. 369 & Yax isa che & $\mathrm{Ar}$ & & II & ME & SAP \\
\hline $\begin{array}{l}\text { Arachnothryx stachyoidea } \\
\text { (Donn.Sm.) Borhidi }\end{array}$ & $\begin{array}{l}\text { A. Durán F. 382, } \\
445\end{array}$ & $\begin{array}{l}\text { Joto che, } \\
\text { A'watan che }\end{array}$ & $\mathrm{Ar}$ & INTR & II & ME & SAP \\
\hline Blepharidium guatemalense Standl. & A. Durán F. 701 & A kakache & $\mathrm{Ar}$ & ARTE, MACO & & & SAP \\
\hline Chiococca alba (L.) Hitchc. & A. Durán F. 655 & & $\mathrm{Li}$ & & & & SAP \\
\hline Chiococca phaenostemon Schltdl. & $\begin{array}{l}\text { A. Durán F. 427, } \\
661\end{array}$ & $\begin{array}{l}\text { Tsiban che, } \\
\text { Kamati che }\end{array}$ & $\mathrm{Ar}$ & LEÑA & II & ME & SAP \\
\hline Chione venosa (Sw.) Urb. & $\begin{array}{l}\text { A. Durán F. 062, } \\
205,364\end{array}$ & $\begin{array}{l}\text { A che koch, } \\
\text { Che koch }\end{array}$ & $\mathrm{Ar}$ & ALFA, MEDI & $\mathrm{VI}$ & $\mathrm{E}$ & SAP \\
\hline Chomelia brachypoda Donn.Sm. & A. Durán F. 1193 & & $\mathrm{Ar}$ & ALFA & III & & SAP \\
\hline Faramea occidentalis (L.) A.Rich. & A. Durán F. 057 & Mojon che & $\mathrm{Ar}$ & MACO & IV & ME & SAP \\
\hline Genipa americana L. & A. Durán F. 254 & Che & $\mathrm{Ar}$ & MACO & V & $\mathrm{E}$ & SAP \\
\hline $\begin{array}{l}\text { Gonzalagunia chiapasensis (Standl.) } \\
\text { Standl. \& Steyerm. }\end{array}$ & A. Durán F. 1208 & & $\mathrm{Ar}$ & ALFA & III & & SAP \\
\hline $\begin{array}{l}\text { Gonzalagunia thyrsoidea (Donn.Sm.) } \\
\text { B.L.Rob. }\end{array}$ & A. Durán F. 165 & Sac oor che & $\mathrm{Ar}$ & MACO & III & $\mathrm{E}$ & SAP \\
\hline $\begin{array}{l}\text { Guettarda combsii subsp. seleriana } \\
\text { (Loes.) Borhidi }\end{array}$ & $\begin{array}{l}\text { A. Durán F. 1254, } \\
1238\end{array}$ & Sak babache & $\mathrm{Ar}$ & & VI & & SAP \\
\hline Guettarda combsii Urb. & A. Durán F. 159 & $\begin{array}{l}\text { Utop sak } \\
\text { babache }\end{array}$ & $\mathrm{Ar}$ & & V & ME & SAP \\
\hline Hamelia calycosa Donn.Sm. & A. Durán F. 167 & Jaxa kak & $\mathrm{Ar}$ & & II & $\mathrm{E}$ & SAP \\
\hline Hamelia longipes Standl. & A. Durán F. 200 & Jayan de che & $\mathrm{Ar}$ & MEDI & II & $\mathrm{E}$ & SAP \\
\hline Hamelia patens Jacq. & A. Durán F. 1224 & & $\mathrm{Ar}$ & MEDI & III & & AVS \\
\hline
\end{tabular}


Apéndice 1. Continuación

\begin{tabular}{|c|c|c|c|c|c|c|c|}
\hline Clado/Familia/Especie & Recolecta & Nombre común & $\begin{array}{l}\text { Forma } \\
\text { vital }\end{array}$ & $\begin{array}{l}\text { Finalidad } \\
\text { de uso }\end{array}$ & Estrato & $\begin{array}{l}\text { Abundancia } \\
\text { relativa }\end{array}$ & Hábitat \\
\hline Hamelia rovirosae Wernham & A. Durán F. 1333 & & $\mathrm{Ar}$ & MEDI & III & $A$ & AVS \\
\hline Hillia tetrandra Sw. & $\begin{array}{l}\text { A. Durán F. 1202, } \\
1210\end{array}$ & & Har & & IV & & SAP \\
\hline $\begin{array}{l}\text { Hoffmannia culminicola Standl. } \\
\text { \& L.O.Williams }\end{array}$ & A. Durán F. 1243 & & $\mathrm{Ar}$ & & III & & SAP \\
\hline $\begin{array}{l}\text { Hoffmannia nicotianifolia (M. } \\
\text { Martens \& Galeotti) L.O.Williams }\end{array}$ & A. Durán F. 632 & & $\mathrm{He}$ & & & & SAP \\
\hline Morinda panamensis Seem. & $\begin{array}{l}\text { A. Durán F. 331, } \\
547\end{array}$ & $\begin{array}{l}\text { Xo yok che, } \\
\text { Nuko xoyok che }\end{array}$ & $\mathrm{Ar}$ & COLO & V & $\mathrm{E}$ & SAP \\
\hline $\begin{array}{l}\text { Notopleura latistipula (Standl.) } \\
\text { C.M.Taylor }\end{array}$ & $\begin{array}{l}\text { A. Durán F. 050, } \\
217\end{array}$ & Welech & $\mathrm{Ab}$ & & II & $\mathrm{E}$ & SAP \\
\hline Notopleura uliginosa (Sw.) Bremek. & $\begin{array}{l}\text { A. Durán F. 045, } \\
155\end{array}$ & $\begin{array}{l}\text { Mumun che, } \\
\text { Jaya re xib }\end{array}$ & $\mathrm{Ab}$ & & II & $\mathrm{E}$ & SAP \\
\hline Palicourea domingensis (Jacq.) DC. & A. Durán F. 420 & $\begin{array}{l}\text { Sayok che } \\
\text { nukux wits }\end{array}$ & $\mathrm{Ar}$ & & V & ME & SAP \\
\hline $\begin{array}{l}\text { Palicourea padifolia (Willd. ex } \\
\text { Schult.) C.M.Taylor \& Lorence }\end{array}$ & A. Durán F. 715 & Abak che & $\mathrm{Ar}$ & & & & SAP \\
\hline $\begin{array}{l}\text { Palicourea tetragona (Donn.Sm.) } \\
\text { C.M.Taylor }\end{array}$ & $\begin{array}{l}\text { A. Durán F. 017, } \\
018,024,028, \\
033,104,710\end{array}$ & $\begin{array}{l}\text { Xo yok, } \\
\text { Xo yok che, } \\
\text { Uchey chanix }\end{array}$ & $\operatorname{Ar}$ & $\begin{array}{l}\text { ALIM, COLO, } \\
\text { LEÑA, INTR }\end{array}$ & II & PA & SAP \\
\hline Psychotria berteroana DC. & A. Durán F. 1200 & & $\mathrm{Ar}$ & & III & & SAP \\
\hline Psychotria costivenia Griseb. & $\begin{array}{l}\text { A. Durán F. 085, } \\
120,656\end{array}$ & $\begin{array}{l}\text { Chiri tuch, } \\
\text { Chur che }\end{array}$ & $\mathrm{He}$ & & I & PA & SAP \\
\hline Psychotria elata (Sw.) Hammel & $\begin{array}{l}\text { A. Durán F. } 037 \text {, } \\
038,146,147\end{array}$ & $\begin{array}{l}\text { Yax che, } \\
\text { Baran che }\end{array}$ & $\mathrm{Ab}$ & & 1 & PA & SAP \\
\hline Psychotria flava Oerst. ex Standl. & A. Durán F. 036 & Ton simin & $\mathrm{Ar}$ & & III & $\mathrm{E}$ & SAP \\
\hline $\begin{array}{l}\text { Psychotria galeottiana (M.Martens) } \\
\text { C.M.Taylor \& Lorence }\end{array}$ & $\begin{array}{l}\text { A. Durán F. 153, } \\
187,257\end{array}$ & Kaka che & $\mathrm{Ar}$ & ALFA, MACO & IV & ME & SAP \\
\hline Psychotria horizontalis Sw. & $\begin{array}{l}\text { A. Durán F. 131, } \\
\text { 160, } 216\end{array}$ & $\begin{array}{l}\text { Mejen wech, } \\
\text { Yox ik mejen, } \\
\text { Amaman che }\end{array}$ & $\mathrm{Ab}$ & MEDI & II & $\mathrm{E}$ & SAP \\
\hline Psychotria panamensis Standl. & $\begin{array}{l}\text { A. Durán F. 113, } \\
203,307,506, \\
706\end{array}$ & $\begin{array}{l}\text { Wech xip, } \\
\text { Yax jara che, } \\
\text { Ukutza che }\end{array}$ & $\operatorname{Ar}$ & MEDI & IV & PA & SAP \\
\hline Psychotria pleuropoda Donn.Sm. & A. Durán F. 202 & Ak lexibe & $\mathrm{Ab}$ & & II & $\mathrm{E}$ & SAP \\
\hline Psychotria poeppigiana Müll.Arg. & A. Durán F. 076 & Yax top che & $\mathrm{He}$ & & II & $\mathrm{E}$ & SAP \\
\hline Psychotria pubescens Sw. & $\begin{array}{l}\text { A. Durán F. 188, } \\
724\end{array}$ & Amaman che & $\mathrm{Ab}$ & & II & $\mathrm{E}$ & SAP \\
\hline $\begin{array}{l}\text { Rogiera stenosiphon (Hemsl.) } \\
\text { Borhidi }\end{array}$ & $\begin{array}{l}\text { A. Durán F. 337, } \\
454\end{array}$ & $\begin{array}{l}\text { Tzo jon che, } \\
\text { Kata che }\end{array}$ & $\mathrm{Ar}$ & CEMI & IV & ME & SAP \\
\hline $\begin{array}{l}\text { Spermacoce laevis Lam. } \\
\text { Rutaceae }\end{array}$ & A. Durán F. 536 & & $\mathrm{He}$ & & & & AVS \\
\hline $\begin{array}{l}\text { Zanthoxylum juniperinum Poepp. } \\
\text { Salicaceae }\end{array}$ & A. Durán F. 103 & Lacte & $\mathrm{Ar}$ & & IV & $\mathrm{E}$ & SAP \\
\hline Casearia aff. aculeata Jacq. & A. Durán F. 378 & Pa chac che & $\mathrm{Ar}$ & $\begin{array}{l}\text { ALIM, MEDI, } \\
\text { LEÑA }\end{array}$ & IV & ME & SAP \\
\hline Casearia bartlettii Lundell & $\begin{array}{l}\text { A. Durán F. 213, } \\
365\end{array}$ & A pa yok che & $\mathrm{Ar}$ & LEÑA & III & $\mathrm{E}$ & SAP \\
\hline
\end{tabular}


Apéndice 1. Continuación

\begin{tabular}{|c|c|c|c|c|c|c|c|}
\hline Clado/Familia/Especie & Recolecta & Nombre común & $\begin{array}{l}\text { Forma } \\
\text { vital }\end{array}$ & $\begin{array}{l}\text { Finalidad } \\
\text { de uso }\end{array}$ & Estrato & $\begin{array}{l}\text { Abundancia } \\
\text { relativa }\end{array}$ & Hábitat \\
\hline $\begin{array}{l}\text { Pleuranthodendron lindenii } \\
\text { (Turcz.) Sleumer }\end{array}$ & A. Durán F. 375 & Ixim che & $\mathrm{Ar}$ & ALFA & V & $\mathrm{E}$ & SAP \\
\hline $\begin{array}{l}\text { Xylosma flexuosa (Kunth) Hemsl. } \\
\text { Santalaceae }\end{array}$ & A. Durán F. 505 & Joris che & $\mathrm{Ar}$ & ALFA & & & SAP \\
\hline Phoradendron nervosum Oliv. & $\begin{array}{l}\text { A. Durán F. 399, } \\
520\end{array}$ & $\begin{array}{l}\text { Sak jara che, } \\
\text { Lelem che }\end{array}$ & Par & & & & SAP \\
\hline $\begin{array}{l}\text { Phoradendron piperoides (Kunth) Trel. } \\
\text { Sapindaceae }\end{array}$ & A. Durán F. 320 & A kukin che & Par & & & & SAP \\
\hline Allophylus cominia (L.) Sw. & A. Durán F. 682 & A taki che & $\mathrm{Ar}$ & LEÑA & & & SAP \\
\hline $\begin{array}{l}\text { Billia rosea (Planch. \& Linden) } \\
\text { C.U.Ulloa \& M.Jørg. }\end{array}$ & $\begin{array}{l}\text { A. Durán F. 249, } \\
346\end{array}$ & Karop che & $\mathrm{Ar}$ & $\begin{array}{l}\text { MACO, JUGE, } \\
\text { JABO }\end{array}$ & $\mathrm{VI}$ & A & SAP \\
\hline Exothea paniculata (Juss.) Radlk. & A. Durán F. 523 & $\begin{array}{l}\text { Wuaran che } \\
\text { koch }\end{array}$ & $\mathrm{Ar}$ & & & & SAP \\
\hline Exothea sp. & A. Durán F. 215 & Stuyu che & $\mathrm{Ar}$ & & II & PA & SAP \\
\hline $\begin{array}{l}\text { Matayba oppositifolia (A.Rich.) } \\
\text { Britton }\end{array}$ & A. Durán F. 383 & Itzin che & $\mathrm{Ar}$ & LEÑA & III & ME & SAP \\
\hline Paullinia costata Schltdl. \& Cham. & A. Durán F. 714 & & $\mathrm{Li}$ & & & & SAP \\
\hline Serjania atrolineata C.Wright & A. Durán F. 355 & $\begin{array}{l}\text { A kura ak, } \\
\text { Max ak }\end{array}$ & $\mathrm{Li}$ & EMBA & V & ME & SAP \\
\hline Serjania caracasana (Jacq.) Willd. & A. Durán F. 168 & Mo ak & $\mathrm{Li}$ & EMBA & IV & PA & SAP \\
\hline $\begin{array}{l}\text { Serjania racemosa Schumach. } \\
\text { Sapotaceae }\end{array}$ & A. Durán F. 694 & Churix che & $\mathrm{Ab}$ & MEDI & & & PCM \\
\hline $\begin{array}{l}\text { Chrysophyllum mexicanum } \\
\text { Brandegee }\end{array}$ & A. Durán F. 396 & Yo och uk & $\mathrm{Ar}$ & $\begin{array}{l}\text { ALIM, MEDI, } \\
\text { LEÑA, MACO }\end{array}$ & V & $\mathrm{E}$ & SAP \\
\hline Manilkara zapota (L.) P.Royen & A. Durán F. 361 & $\begin{array}{l}\text { Ya, Chico } \\
\text { zapote }\end{array}$ & $\mathrm{Ar}$ & $\begin{array}{l}\text { INTR, ALIM, } \\
\text { MACO, CHIC }\end{array}$ & V & $\mathrm{E}$ & SAP \\
\hline $\begin{array}{l}\text { Pouteria campechiana (Kunth) } \\
\text { Baehni }\end{array}$ & A. Durán F. 220 & Hotlia wits & Ar & $\begin{array}{l}\text { ALIM, MACO, } \\
\text { MEDI }\end{array}$ & V & $E$ & SAP \\
\hline Pouteria durlandii (Standl.) Baehni & A. Durán F. 189 & $\begin{array}{l}\text { Tuch kambul } \\
\text { che }\end{array}$ & $\mathrm{Li}$ & & IV & PA & SAP \\
\hline Pouteria reticulata (Engl.) Eyma & A. Durán F. 1199 & Juch & $\mathrm{Ar}$ & & III & & SAP \\
\hline $\begin{array}{l}\text { Sideroxylon portoricense subsp. } \\
\text { minutiflorum (Pittier) T.D.Penn. }\end{array}$ & $\begin{array}{l}\text { A. Durán F. 610, } \\
717\end{array}$ & $\begin{array}{l}\text { Chac subanche, } \\
\text { Nukuch subanche }\end{array}$ & $\mathrm{Ar}$ & ARTE & & & SAP \\
\hline Sideroxylon salicifolium (L.) Lam. & $\begin{array}{l}\text { A. Durán F. 175, } \\
419\end{array}$ & $\begin{array}{l}\text { Wuaite, Chakia, } \\
\text { Huech che }\end{array}$ & $\mathrm{Ar}$ & $\begin{array}{l}\text { MACO, INTR, } \\
\text { LEÑA, ARTE }\end{array}$ & V & MA & SAP \\
\hline \multicolumn{8}{|l|}{ Solanaceae } \\
\hline Cestrum nocturnum L. & A. Durán F. 646 & & $\mathrm{Ab}$ & ORNA & & & PCM \\
\hline $\begin{array}{l}\text { Lycianthes cuchumatanensis J.L. } \\
\text { Gentry }\end{array}$ & $\begin{array}{l}\text { A. Durán F. 1250, } \\
1282\end{array}$ & Yoch chaca & $\mathrm{Ar}$ & & III & & SAP \\
\hline Lycopersicon esculentum Mill. & A. Durán F. 595 & Pak, Tomate & $\mathrm{He}$ & ALIM & & & PCM \\
\hline Physalis gracilis Miers & $\begin{array}{l}\text { A. Durán F. 545, } \\
626\end{array}$ & Pakan pak & $\mathrm{He}$ & ALIM & & & AVS \\
\hline $\begin{array}{l}\text { Schultesianthus leucanthus } \\
\text { (Donn.Sm.) Hunz. }\end{array}$ & $\begin{array}{l}\text { A. Durán F. 100, } \\
340\end{array}$ & $\begin{array}{l}\text { Kan ak, Kurak, } \\
\text { Chia }\end{array}$ & $\mathrm{Li}$ & & V & $\mathrm{E}$ & SAP \\
\hline Solanum americanum Mill. & $\begin{array}{l}\text { A. Durán F. 624, } \\
637\end{array}$ & Ach yuk & $\mathrm{He}$ & & & & AVS \\
\hline Solanum nudum Dunal & $\begin{array}{l}\text { A. Durán F. 535, } \\
602\end{array}$ & Kaka lobí & $\mathrm{He}$ & MEDI & & & AVS \\
\hline
\end{tabular}


Apéndice 1. Continuación

\begin{tabular}{|c|c|c|c|c|c|c|c|}
\hline Clado/Familia/Especie & Recolecta & Nombre común & $\begin{array}{l}\text { Forma } \\
\text { vital }\end{array}$ & $\begin{array}{l}\text { Finalidad } \\
\text { de uso }\end{array}$ & Estrato & $\begin{array}{l}\text { Abundancia } \\
\text { relativa }\end{array}$ & Hábitat \\
\hline \multicolumn{8}{|l|}{ Styracaceae } \\
\hline $\begin{array}{l}\text { Styrax warscewiczii Perkins } \\
\text { Tapisciaceae }\end{array}$ & \multicolumn{6}{|c|}{ Tapisciaceae } & SAP \\
\hline Huertea cubensis Griseb. & $\begin{array}{l}\text { A. Durán F. 1125, } \\
1140\end{array}$ & Pach jup che & $\operatorname{Ar}$ & ALFA & IV & & SAP \\
\hline \multicolumn{8}{|l|}{ Ulmaceae } \\
\hline $\begin{array}{l}\text { Ulmus mexicana (Liebm.) Planch. } \\
\text { Urticaceae }\end{array}$ & A. Durán F. 357 & Sac pucte & Ar & MACO & V & $\mathrm{E}$ & SAP \\
\hline Boehmeria ramiflora Jacq. & A. Durán F. 1359 & Mumun lobí & $\mathrm{He}$ & & II & A & AVS \\
\hline Cecropia obtusifolia Bertol. & A. Durán F. 172 & Koch & $\mathrm{Ar}$ & MEDI & IV & ME & SAP \\
\hline Cecropia peltata L. & A. Durán F. 006 & Koch & Ar & $\begin{array}{l}\text { ALFA, MACO, } \\
\text { LEÑA, MEDI }\end{array}$ & III & ME & SAP \\
\hline Coussapoa oligocephala Donn.Sm. & A. Durán F. 323 & Nukuch kopo & Har & & VI & $\mathrm{E}$ & SAP \\
\hline Myriocarpa heterostachya Donn.Sm. & A. Durán F. 440 & Saki che & $\operatorname{Ar}$ & & & & SAP \\
\hline Pilea falcata Liebm. & A. Durán F. 635 & & $\mathrm{He}$ & & & & SAP \\
\hline $\begin{array}{l}\text { Urera caracasana (Jacq.) Gaudich. } \\
\text { ex Griseb. }\end{array}$ & A. Durán F. 683 & Apapach che & $\mathrm{Ab}$ & & & & SAP \\
\hline \multicolumn{8}{|l|}{ Verbenaceae } \\
\hline Citharexylum hexangulare Greenm. & A. Durán F. 084 & Che & $\mathrm{Ab}$ & & III & PA & SAP \\
\hline Lantana achyranthifolia Desf. & A. Durán F. 582 & & $\mathrm{He}$ & & & & AVS \\
\hline Lantana camara L. & $\begin{array}{l}\text { A. Durán F. 548, } \\
550,1246\end{array}$ & $\begin{array}{l}\text { A Chak chobi, } \\
\text { chak chop che }\end{array}$ & $\mathrm{He}$ & MEDI & I & & AVS \\
\hline Lantana trifolia L. & $\begin{array}{l}\text { A. Durán F. 550, } \\
593\end{array}$ & Chak chop che & $\mathrm{Ab}$ & & & & AVS \\
\hline $\begin{array}{l}\text { Lippia alba (Mill.) N.E.Br. ex Britton } \\
\text { \& P.Wilson }\end{array}$ & A. Durán F. 670 & & $\mathrm{Ab}$ & MEDI & & & AVS \\
\hline Lippia myriocephala Schltdl. \& Cham. & A. Durán F. 072 & Che & $\mathrm{Ab}$ & MEDI, MACO & III & PA & SAP \\
\hline $\begin{array}{l}\text { Stachytarpheta cayennensis } \\
\text { (Rich.) Vahl }\end{array}$ & $\begin{array}{l}\text { A. Durán F. 538, } \\
666\end{array}$ & Utzak kax & $\mathrm{He}$ & MEAN & & & AVS \\
\hline \multicolumn{8}{|l|}{ Violaceae } \\
\hline $\begin{array}{l}\text { Orthion malpighiifolium (Standl.) } \\
\text { Standl. \& Steyerm. }\end{array}$ & A. Durán F. 198 & Sac che & $\mathrm{Ar}$ & & V & ME & SAP \\
\hline Rinorea hummelii Sprague & $\begin{array}{l}\text { A. Durán F. 263, } \\
371\end{array}$ & Maka che & $\operatorname{Ar}$ & MEDI & III & PA & SAP \\
\hline \multicolumn{8}{|l|}{ Vitaceae } \\
\hline Cissus alata Jacq. & A. Durán F. 089 & O tak ak & $\mathrm{Li}$ & ALFA & IV & $\mathrm{E}$ & SAP \\
\hline Cissus biformifolia Standl. & $\begin{array}{l}\text { A. Durán F. 259, } \\
413,669\end{array}$ & $\begin{array}{l}\text { Stak chup, } \\
\text { Nuch ta ak }\end{array}$ & $\mathrm{Li}$ & & IV & PA & SAP \\
\hline Cissus cacuminis Standl. & A. Durán F. 1353 & Mejen sus & $\mathrm{Te}$ & & II & & SAP \\
\hline Cissus sicyoides L. & A. Durán F. 647 & $\begin{array}{l}\text { Mejen sak ta ak, } \\
\text { Utza kachup }\end{array}$ & $\mathrm{Te}$ & MEDI & & & AVS \\
\hline $\begin{array}{l}\text { Cissus verticillata (L.) Nicolson } \\
\text { \& C.E.Jarvis }\end{array}$ & A. Durán F. 1280 & Utza kachup & $\mathrm{Te}$ & & & & SAP \\
\hline Vitis bourgaeana Planch. & A. Durán F. 063 & Tzuts & $\mathrm{Te}$ & $\begin{array}{l}\text { ALIM, FUAG, } \\
\text { FIBR }\end{array}$ & V & ME & SAP \\
\hline $\begin{array}{l}\text { Vitis tiliifolia Humb. \& Bonpl. } \\
\text { ex Schult. }\end{array}$ & A. Durán F. 654 & $\begin{array}{l}\text { Nukux sac } \\
\text { tzuts }\end{array}$ & $\mathrm{Li}$ & ALIM & & & SAP \\
\hline \multicolumn{8}{|l|}{ Vochysiaceae } \\
\hline Vochysia guatemalensis Donn. Sm. & A. Durán F. 385 & Naxa ya che & $\mathrm{Ar}$ & MACO & VI & PA & SAP \\
\hline
\end{tabular}

